\title{
Higher Long-Term Soil Moisture Increases Organic Carbon Accrual Through Microbial Conversion of Organic Inputs
}

Itamar A. Shabtai ${ }^{1 *}$, Srabani Das², Thiago M. Inagaki ${ }^{3}$, Behrooz Azimzadeh $^{1}$, Brian Richards ${ }^{4}$, Carmen Enid Martínez ${ }^{1}$, Ingrid Kögel-Knabner ${ }^{3,6}$, and Johannes Lehmann ${ }^{1,5}$

${ }^{1}$ Soil and Crop Sciences, School of Integrative Plant Science, Cornell University, Ithaca, NY, 14850,

${ }^{2}$ Center for Carbon Management and Sequestration, The Ohio State University, Columbus, OH, 43210, USA

${ }^{3}$ Chair of Soil Science, School of Life Sciences, Technical University of Munich, 85354 Freising,

Germany 


\section{This is a preprint submitted to Earth ArXiv and has not been peer reviewed}

15

\section{Abstract}

High long-term soil moisture may either stimulate or inhibit soil organic carbon (SOC) losses through changes to mineral and chemical composition, and resultant organo-mineral interactions. Yet, the trade-off between mineralization and accrual of SOC under long-term variation in unsaturated soil moisture remains an uncertainty. In this study, we tested the underexplored relationships between long-term soil moisture and organo-mineral chemical composition, and its implications for SOC persistence. The results provide new insights into SOC accrual mechanisms under different long-term moisture levels commonly observed in well-drained soils. Differences in long-term mean volumetric water content ranging from 0.4 $0.63(\mathrm{v} / \mathrm{v})$ on fallow plots in an experimental field in New York, USA, were positively correlated with SOC contents $\left(\mathrm{R}^{2}=0.228 ; \mathrm{P}=0.019, n=20\right)$, mineral-associated organic matter $(\mathrm{MAOM})\left(\mathrm{R}^{2}=0.442 ; \mathrm{P}=\right.$ $0.001 ; n=20)$ and occluded particulate organic matter $(\mathrm{oPOM})$ contents $\left(\mathrm{R}^{2}=0.178 ; \mathrm{P}=0.033 ; n=20\right)$. Higher long-term soil moisture decreased the relative content of sodium pyrophosphate extractable Fe $\left(\mathrm{R}^{2}\right.$ $=0.33 ; \mathrm{P}<0.005 ; n=20)$, increased that of sodium dithionite extractable $\mathrm{Fe}\left(\mathrm{R}^{2}=0.443 ; \mathrm{P}<0.001 ; n=\right.$ 20), and increased the overall importance of non-crystalline Al pools (extracted with sodium pyrophosphate and hydroxylamine extractable) for SOC retention. Higher long-term soil moisture supported up to a four-fold increase in microbial biomass (per unit SOC), and lower C:N ratios in MAOM fractions of high-moisture soils (from $\mathrm{C}: \mathrm{N} 9.5$ to $9, \mathrm{R}^{2}=0.267, \mathrm{P}=0.011, n=20$ ). This was reflected by a $15 \%$ and $10 \%$ greater proportion of oxidized carboxylic-C to aromatic-C and O-alkyl C, respectively, as measured with ${ }^{13} \mathrm{C}-\mathrm{NMR}$, and a more pronounced FTIR signature of $\mathrm{N}$-containing proteinaceous compounds in high-moisture MAOM fractions, reflective of microbial metabolites. SOC accrual increased with increasing soil moisture $(\mathrm{P}=0.019)$, exchangeable $\mathrm{Ca}^{2+}(\mathrm{P}=0.013)$, and pyrophosphate-extractable $\mathrm{Al}$ content $(\mathrm{P}=0.0001)$ and $\mathrm{Al} / \mathrm{Fe}$ ratio $(\mathrm{P}=0.017)$. Taken together, our results show that high long-term soil moisture resulted in SOC accrual by enhancing microbial conversion of plant inputs to metabolites that interact with reactive minerals. 


\section{Introduction}

Soils comprise the largest terrestrial store of organic carbon (OC) (Friedlingstein et al., 2019) and play a substantial role in the global C cycle (Scharlemann et al., 2014). As a result, increasing soil organic carbon (SOC) storage by decreasing losses to $\mathrm{CO}_{2}$ may be a feasible strategy to withdraw atmospheric $\mathrm{CO}_{2}$ and partially offset anthropogenic emissions driving climate change (Minasny et al., 2017). As climate change is expected to drastically alter soil moisture conditions globally (Seneviratne et al., 2010; Grillakis, 2019), a better understanding of the trade-off between SOC mineralization and stabilization under longterm changes to soil moisture is needed to manage SOC stocks (Falloon et al., 2011). Importantly, unlike soil temperature which is expected to rise and increase SOC mineralization (Soong et al., 2021), soil moisture is a parameter that can be managed - through irrigation, controlled drainage, and wetland restoration - and can indirectly curb soil warming through evapotranspiration (Seneviratne et al., 2010).

Soil moisture controls SOC turnover and storage by regulating fundamental processes such as soil biotic activity (Moyano et al., 2013), solute transport, gaseous exchange, and mineral weathering (Schjønning et al., 2003; Moyano et al., 2013; Kramer and Chadwick, 2018). Short-term increases in soil moisture are known to stimulate microbial activity (Ghezzehei et al., 2019), yet long-term increases may either stimulate or decrease SOC losses by changes to vegetation (Chen et al., 2020), mineral composition (Doetterl et al., 2015; Khomo et al., 2017), SOC chemical composition (Hall et al., 2018) and resultant organo-mineral interactions (Mikutta et al., 2009; Kramer et al., 2012). Most of these studies evaluated broad gradients in precipitation, soil mineral properties, or soil age, which inevitably interact in complex ways. Yet, the direct effects of long-term differences in soil moisture on SOC turnover has received little attention (Moyano et al., 2013), largely due to the challenge of isolating measurable variation in long-term soil moisture at field scale. This has limited our ability to predict and manage SOC stocks in the face of changing soil moisture conditions (Todd-Brown et al., 2014; Berg and Sheffield, 2018).

SOC is widely considered to consist of microbial residues and necromass (Schurig et al., 2013; Zhu et al., 2020) which have been protected from further decomposition through interactions with the mineral 
64 matrix (Kleber et al., 2021). Therefore, SOC turnover is largely dependent on the efficiency of microbial 65 conversion of organic inputs into microbial biomass (i.e., substrate use efficiency), with higher efficiency 66 indicative of greater C storage in the soil as microbial biomass (Manzoni et al., 2012) and mineral67 associated SOC (Zhu et al., 2020). Long-term soil moisture affects this efficiency by regulating diffusion 68 rates of substrates used by microbial communities (Butcher et al., 2020). Low water content inhibits 69 diffusion of dissolved compounds in the soil solution due to thinning of water films in soil pores, increased 70 flow path length and solution viscosity (Butcher et al., 2020), thus limiting the probability of encounters 71 between microbes, extracellular enzymes, and substrates. Recent work has shown that limited substrate 72 diffusion at low soil water contents can decrease microbial carbon use efficiency (Butcher et al., 2020). 73 Additionally, increased microbial activity at high moisture conditions can enhance the conversion of high 74 molecular weight, hydrophobic plant inputs into soluble, charge-containing, low molecular weight 75 compounds which tend to interact with mineral surface (Lehmann and Kleber, 2015). Thus, SOC cycled 76 under higher long-term soil moisture may have greater persistence and result in net SOC accrual, yet 77 experimental evidence is lacking.

The amount and nature of soil minerals often control the content, composition, and persistence of 79 adsorbed or occluded SOC (Sanderman et al., 2014; Rasmussen et al., 2018; Kleber et al., 2021). SOC may 80 predominantly interact with non-crystalline or crystalline oxide phases, or with phyllosilicate clay minerals, 81 depending on their type and relative content in the soil (Mikutta et al., 2006; Khomo et al., 2017; Hall et 82 al., 2018; Rowley et al., 2018). Furthermore, long-term differences in soil moisture can result in different 83 rates of chemical weathering of minerals which can in turn alter their reactivity and capacity to retain SOC, 84 with implications for SOC stabilization (Doetterl et al., 2015). However, the effects of mineral composition 85 on organo-mineral interactions may be confounded by other factors such as climate and vegetation.

86 Therefore, we aimed to investigate the effects of increasing long-term soil moisture under unsaturated 87 conditions on microbial turnover of SOC, SOC storage in soil density fractions, and the chemical 88 composition of organo-mineral associations. In addition, we probed the effect of these variables on the 
89 persistence of SOC by determining mineralizability in laboratory incubations. We hypothesized that (1)

90 soils experiencing higher long-term moisture that is more conducive to microbial activity will have more

91 oxidized SOC functional groups and higher contents of non-crystalline oxide phases due to higher

92 decomposition and weathering, respectively, and (2) that organo-mineral interactions in high-moisture soils

93 will support SOC accrual.

\section{2. Materials and Methods}

\subsection{Field site}

The field site located near Ithaca, New York, USA (42N28.20',76W25.94'), included three primary soil series: well drained Canaseraga (coarse-silty, mixed, active, mesic typic Fragiudept), slightly poorly drained Dalton (Coarse-silty, mixed, active, mesic aeric Fragiaquept) and poorly drained Madalin (fine, illitic, mesic mollic Endoaqualf) (Das et al., 2018). The epipedon texture is primarily silt loam, characterized by dense subsoil fragipans and recurring perched water tables resulting from the restrictive subsoil layers. The field topography is undulating, with slopes varying from 0 to $8 \%$ (and a small area with short slopes of up to $15 \%$ on the eastern edge). The mean annual temperature and precipitation at the site are $10{ }^{\circ} \mathrm{C}$ and $940 \mathrm{~mm}$, respectively.

Four fallow plots were laid out to capture the range of soil moisture regimes, varying from moderately well-drained to poorly drained (Das et al., 2019). The characteristic soil moisture regime along five sampling subplots in each of the four plots was previously determined following a soil moisture measurement campaign carried out from 2011 to 2015 (Das et al., 2018) (See Figure S1 for 2011-2018 data). The volumetric water content of each sampling site's surface layer was measured via replicated timedomain reflectometry (TDR) and the relative soil water content was determined by dividing the sample location volumetric water content by the mean field value for that sampling event. For each of over 40 sampling events, a normalized moisture value was calculated for each of 80 sampling sites (including the 20 fallow sites and 60 other non-fallow sites not reported here) based on the multi-year mean of its relative 
113 water content. Thus, the multi-year mean cumulatively represents several thousand readings at the field

114 (Das et al., 2018). The normalized moisture values were binned into quantiles (Das et al., 2018) (Table S1).

115 The driest subplots (denoted as Q1) had the lowest water contents relative to the field mean, and the wettest 116 subplots (denoted as Q5) had the highest water contents relative to the field mean.

117 The plant cover at the time of sampling consisted of fallow (unmowed for circa 10 years) grasses

118 dominated by legacy reed canarygrass (Phalaris arundinaceae L.) interspersed with numerous other 119 grasses and broadleaf forbs. The plots were undisturbed aside from small $\left(1 \mathrm{~m}^{2}\right)$ hand harvests at subplots 120 after dormancy to characterize yields for comparison with other cropping treatments.

\section{$121 \quad$ 2.2 Sampling method}

Soils were sampled from the surface Ap layer (0 - $0.15 \mathrm{~m}$ depth) in October 2018 at two locations equidistant $(1.2 \mathrm{~m})$ from the center of each of 20 sampling points (marked by a permanent flag). Approximately two $\mathrm{kg}$ of soil were dug from each of the two locations, composited in a bucket, mixed, and

131 (Das et al., 2019).

\section{$132 \quad 2.3$ Soil analyses}

\section{$133 \quad$ 2.3.1 Soil characterization}

Gravimetric and hygroscopic water contents were determined on field moist and air-dry subsamples, respectively, after drying each to constant weight at $105^{\circ} \mathrm{C}$. Gravimetric soil water content at saturation, used to calculate the water filled pore space, was determined as previously described (DeCiucies et al., 2018). Soil pH was measured on 1:2.5 soil:deionized water extractions. Exchangeable cations were 
138 extracted using $1 \mathrm{~N}$ ammonium acetate at $\mathrm{pH} 7$ and measured on an inductively coupled plasma

139 spectrometer (Thermo iCAP 6000 series).

\section{$140 \quad$ 2.3.2 Soil fractionation}

We used a combination of size and density fractionation to isolate operationally defined - but

ecologically relevant - fractions. Soil samples (10 g) were gently agitated for $10 \mathrm{~s}$ with $35 \mathrm{~mL}$ of sodium polytungstate (SPT) adjusted to a density of $1.65 \mathrm{Mg} \mathrm{m}^{-3}$. The samples were left to settle overnight, centrifuged (3000 RCF, $30 \mathrm{~min}$ ), filtered (GF/F, $0.7 \mu \mathrm{m}$ glass fiber filter), and washed with $500 \mathrm{~mL}$ of deionized water. The obtained material is referred to as the free particulate organic matter (fPOM). Fresh SPT solution (35 mL, 1.65 $\mathrm{Mg} \mathrm{m}^{-3}$ ) was added to the samples and a vortex was used to re-disperse the soil.

147 The samples were sonicated (XL 2020, QSonica, Newtown, CT, USA) at $350 \mathrm{~J} \mathrm{~mL}^{-1}$ of energy (operated at $14875 \mathrm{~J} \mathrm{~s}^{-1}$ ), left overnight to allow the particles to settle, and centrifuged (3000 RCF, $45 \mathrm{~min}$ ). The floating 149 material, referred to as the occluded particulate organic matter fraction (oPOM), was isolated as described 150 above. The remaining pellet was washed with deionized water and centrifuged (3000 RCF, $30 \mathrm{~min}$ ) three 151 times to remove the SPT (supernatant density was $1 \pm 0.02 \mathrm{Mg} \mathrm{m}^{-3}$ ). Next, the soils were shaken end-to-end 152 with sodium hexametaphosphate $(35 \mathrm{~mL}, 0.5 \% \mathrm{w} / \mathrm{v})$ for 16 hours and wet sieved $(53 \mu \mathrm{m})$ to separate the 153 sand sized fraction (material remaining on the sieve) from the silt and clay size fractions (material passing 154 the sieve). The material passing the sieve was referred to as the mineral associated organic matter

155 (MAOM) fraction. The MAOM and sand fractions were transferred to a pre-tared aluminum tin and dried at $60{ }^{\circ} \mathrm{C}$. The four obtained fractions - fPOM, oPOM, MAOM, and sand - were weighed, ball milled 157 (except the sand), and stored. Total C, N, and isotope ratios of the fractions (except the sand) and bulk soil 158 samples were measured using a Delta V Isotope Ratio Mass Spectrometer (Thermo Scientific, Germany) 159 coupled to a Carlo Erba NC2500 Elemental Analyzer (Italy). We assumed total C equaled organic C since 160 these soil samples did not contain carbonates (Das et al., 2018) and soil $\mathrm{pH}$ was always $<7$. The mean 161 mass recovery was $102 \%$. Recovery of C ranged from $96-109 \%$ and recovery of $\mathrm{N}$ ranged from 98 - 
$162106 \%$. Sand was assumed to contain zero C and N. The average C concentrations in fPOM and oPOM were

$16335 \%$ and $25 \%$, respectively, indicating that some minerals were present in these isolated fractions.

\section{$164 \quad$ 2.3.3 Oxide extraction}

We performed a sequential oxide extraction following a modified protocol (Heckman et al., 2018) using sodium pyrophosphate (PY), hydroxylamine hydrochloride (HH), and sodium dithionite (DITH) to

167 sequentially release SOC retained by different forms of soil $\mathrm{Al}$ and $\mathrm{Fe}$. Based on published extraction 168 protocols (Ross et al., 1985; Parfitt and Childs, 1988; Wagai and Mayer, 2007; Courchesne and Turmel,

182 inductively coupled plasma spectrometer (Thermo iCAP 6000 series). The concentration of OC in each 183 extract, considered the $\mathrm{C}$ associated with $\mathrm{Al}$ and $\mathrm{Fe}$, was measured by combustion catalytic oxidation

184 (TOC-VCPN TOC analyzer Shimadzu, Japan). 


\subsection{Spectroscopic studies}

\subsubsection{Fourier Transform Infrared (FTIR) spectroscopy}

FTIR spectra were collected on a Vertex 70 spectrometer (Bruker Corp., Billerica, MA) equipped with an ATR sampling accessory (GladiATR, Pike Technologies, Madison, WI). Spectra were collected on dry $\left(60^{\circ} \mathrm{C}\right)$ ball-milled samples $(n=20)$ of soils, MAOM, fPOM, and oPOM fractions, and on ashed (500 ${ }^{\circ} \mathrm{C}$ for $3 \mathrm{~h}$ ) MAOM samples. Spectra representing an average of 64 scans were collected from 450 to 4500 $\mathrm{cm}^{-1}$ at a resolution of $4 \mathrm{~cm}^{-1}$. Replicate spectra for each sample $(n=3)$ were baseline corrected, normalized, and averaged. To identify features originating from organic constituents, spectra of ashed MAOM were subtracted from non-ashed MAOM samples, and smoothed (17-point Savitsky-Golay smoothing). Spectral processing was performed using the OPUS 7.2 software (Bruker Corp., Billerica, MA). ATR-FTIR vibrational assignments of organic and inorganic constituents were based on previous publications (Lehmann et al., 2007; Parikh et al., 2014; Fine et al., 2018).

\subsection{2 ${ }^{13}$ C Nuclear Magnetic Resonance (NMR)}

The molecular structure of organic matter in the bulk soil and soil fractions was analyzed using ${ }^{13} \mathrm{C}$ NMR spectroscopy (Biospin DSX 200 NMR spectrometer, Bruker, Rheinstetten, Germany) with a contact 
209 time of $0.001 \mathrm{sec}$ with a pulse delay of $0.4 \mathrm{sec}$ for bulk soil and silt and clay fractions and $1 \mathrm{sec}$ for fPOM

210 and oPOM fractions. At least 100,000 accumulated scans were performed. The spectra were integrated

211 using four major chemical shift regions: 0 to $45 \mathrm{ppm}$ (alkyl-C), 45 to $110 \mathrm{ppm}$ (O/N-alkyl-C), 110 to 160

212 (aryl-C), and 160 to 220 ppm (carboxyl-C) (Knicker and Lüdemann, 1995). Sample pre-treatment with

213 hydrofluoric acid was not necessary to obtain a well-resolved spectrum. We applied a molecular mixing

214 model (Nelson and Baldock, 2005) to estimate the proportions of biochemical component equivalents from

$215{ }^{13} \mathrm{C}$ NMR spectral regions and N:C ratios. The biochemical components of the model are carbohydrate, 216 protein, lignin, lipid, char, and carbonyl.

\section{7}

\subsubsection{Carbon K-edge Near Edge X-Ray Absorption Fine Structure (NEXAFS)}

SOC chemical composition in bulk soil and soil fractions was analyzed with C K-edge NEXAFS collected at the spherical grating monochromator (SGM) beamline of the Canadian Light Source (Saskatoon, SK). The beamline is equipped with a silicon drift detector (SDD) for partial fluorescence yield (PFY). Samples were deposited on gold (Au)-coated silicon wafers, and air dried. Partial fluorescence yield (PFY) scans (60s) were collected with an $\sim 50$ x $50 \mu \mathrm{m}$ probe in slew mode. The PFY with maximum C signal (detector $90^{\circ}$ to incident beam) was normalized to the PFY scattering signal from a clean Aucoated Si wafer to account for in-line C contamination. The spectra were edge-normalized (edge step=1) and flattened in Athena (Demeter 0.9.25) (Ravel and Newville, 2005). SOC composition was assessed by comparing peak height ratios of the 3 primary spectral features: aromatic $(\mathrm{C}=\mathrm{C})$ at $\sim 285.6 \mathrm{eV}$, substituted aromatic (e.g., $\mathrm{C}=\mathrm{C}-\mathrm{OH})$ at $\sim 286.7 \mathrm{eV}$, and carboxylic $(\mathrm{C}=\mathrm{O}-\mathrm{OH})$ at $\sim 288.7 \mathrm{eV}$ (Solomon et al., 2009; Heymann et al., 2011). Peak heights were determined by the Gaussian function fitting algorithm in Fityk v. 1.3.1 (Wojdyr, 2010), identifying the maximum of a Gaussian function of full-width half maximum $(\mathrm{FWHM})=0.6 \mathrm{eV}($ Possinger et al., 2020).

\subsection{Heterotrophic respiration incubations}

For the incubation experiment, soil samples were thawed and air dried. $5 \mathrm{~g}$ from each soil sample were weighed in triplicate into $60 \mathrm{~mL}$ Qorpak vials, which were placed in $473 \mathrm{~mL}$ Mason jars along with a 
$23420 \mathrm{~mL}$ glass vial containing a $\mathrm{CO}_{2} \operatorname{trap}(15 \mathrm{~mL} \mathrm{KOH}, 0.18 \mathrm{M})$ made with $\mathrm{CO}_{2}$-free deionized water. $\mathrm{CO}_{2-}$

235 free deionized water $(5 \mathrm{~mL})$ was added to the bottom of the jar to maintain a humid atmosphere. To

236 account for the small amount of $\mathrm{CO}_{2}$ present in the jar, measurements from blank jars with no soil were

237 used. Samples were hydrated to a moisture level equivalent to $50 \%$ of water filled pore space with

238 deionized water and incubated for 53 days at $20^{\circ} \mathrm{C}$ in the dark. On days $2,7,18,33$, and 53 the jars were

239 opened, and the electrical conductivity of the $\mathrm{KOH}$ solutions was determined. After each measurement, the

$240 \mathrm{CO}_{2}$ traps were replaced with fresh $\mathrm{KOH}$ solutions in new vials, and fresh deionized water was added to

241 the bottom of the jar. At each sampling event, the average $(n=3)$ electrical conductivity value of the $\mathrm{KOH}$

242 solution from the blank jars was subtracted from each jar's KOH electrical conductivity value. This

243 corrected value was then converted into volume of $\mathrm{CO}_{2}$ released by the sample using a standard curve, and

244 further converted to mass $\mathrm{C}-\mathrm{CO}_{2}$ by applying the ideal gas law. The standard calibration curve was made

245 by injecting known of volumes of $99.99 \% \mathrm{CO}_{2}$ (Airgas, Inc, Elmira, NY) into septa-lidded Mason jars

246 containing empty Qorpak vials, $\mathrm{CO}_{2}$ traps, and $5 \mathrm{~mL} \mathrm{CO}_{2}$-free water on the bottom. The electrical

247 conductivity of the $\mathrm{KOH}$ solution was measured 24 hours after injection. Cumulative respiration was

248 reported per unit soil (termed mineralization; $\mathrm{mg} \mathrm{CO}_{2}-\mathrm{C} / \mathrm{g}$ soil), and per unit $\mathrm{SOC}$ (termed mineralizability;

$249 \mathrm{mg} \mathrm{CO} 2-\mathrm{C} / \mathrm{g} \mathrm{SOC})$.

\section{$250 \quad 2.6$ Statistical methods}

All statistical analyses were done in $\mathrm{R}$ (Version 4.04). Linear regression of response variables to normalized moisture was performed using the $l m$ function. The effects of normalized moisture values and soil fraction on response variables were analyzed using ANOVA, followed by Tukey's HSD post hoc test to determine significant differences between treatments. Pearson's correlation matrix was plotted using the corrplot package. Partial least squares (PLS) regression models were constructed using the mdatools package, to identify the variables that best explain SOC content, mineralization, and mineralizability. PLS regression models reduce dimensionality and create components that maximize the covariance between predictor and response variables. As such, PLS models are especially useful in datasets that contain a 
259 similar number of predictor variables and observations, and/or when predictors are highly correlated.

260 Selectivity Ratio and Variable Importance in Projection tests were used to inform variable selection.

261 Variable Importance for Projection provided the best goodness of fit for all models, which was evaluated 262 based on the highest cross-validated $\mathrm{R}^{2}\left(\mathrm{R}_{\mathrm{cv}}^{2}\right)$, and lowest root mean of square error (RMSE).

\section{3. Results}

\section{$264 \quad 3.1$ Soil organic matter fractions}

SOC and TN content increased with increasing normalized moisture value $\left(\mathrm{R}^{2}=0.228, \mathrm{P}=0.019\right.$, and $\mathrm{R}^{2}=0.249, \mathrm{P}=0.014$, respectively) (Figure 1). The amount of oPOM and MAOM per unit mass of soil increased with increasing normalized moisture $\left(\mathrm{R}^{2}=0.178, \mathrm{P}=0.033\right.$, and $\mathrm{R}^{2}=0.442, \mathrm{P}<0.001$, respectively), but fPOM content did not $(\mathrm{P}=0.9)$ (Figure 1). However, the proportion of $\mathrm{C}$ in each fraction per unit SOC did not differ across normalized moisture values (Figure S2).

\section{$\mathrm{C}: \mathrm{N}$ ratios decreased in the order of roots $>$ shoots $>\mathrm{fPOM}>\mathrm{oPOM}>\mathrm{MAOM} \approx$ bulk soil but were} not significantly different across normalized soil moisture values (Figure S3 and Table S2), apart from the $\mathrm{C}: \mathrm{N}$ ratio of MAOM, which significantly decreased with increasing soil moisture level $\left(\mathrm{R}^{2}=0.267, \mathrm{P}=\right.$ 0.011) (Figure 2A). The $\delta^{13} \mathrm{C}$ values (mean \pm sd) in the bulk soil $(-27.53 \pm 0.3 \%$ ) and MAOM (-27.35 \pm 0.3 $\%$ ) fractions were significantly higher than those of the fPOM $(-28.37 \pm 0.5 \%$ o $)$ and oPOM $(-28.80 \pm 0.4 \%$ ) fractions and plant biomass $(\mathrm{P}<0.0001)$, though the interaction of normalized moisture and fraction on $\delta^{13} \mathrm{C}$ was not significant (Figure S4, Table S2). Additionally, $\delta^{13} \mathrm{C}$ values of fPOM, oPOM, MAOM fractions and bulk soils decreased with increasing normalized moisture values (Figure S4). Normalized soil moisture or its interaction with soil fraction did not significantly affect the $\delta^{15} \mathrm{~N}$ values (Figure S4 and Table S2). 

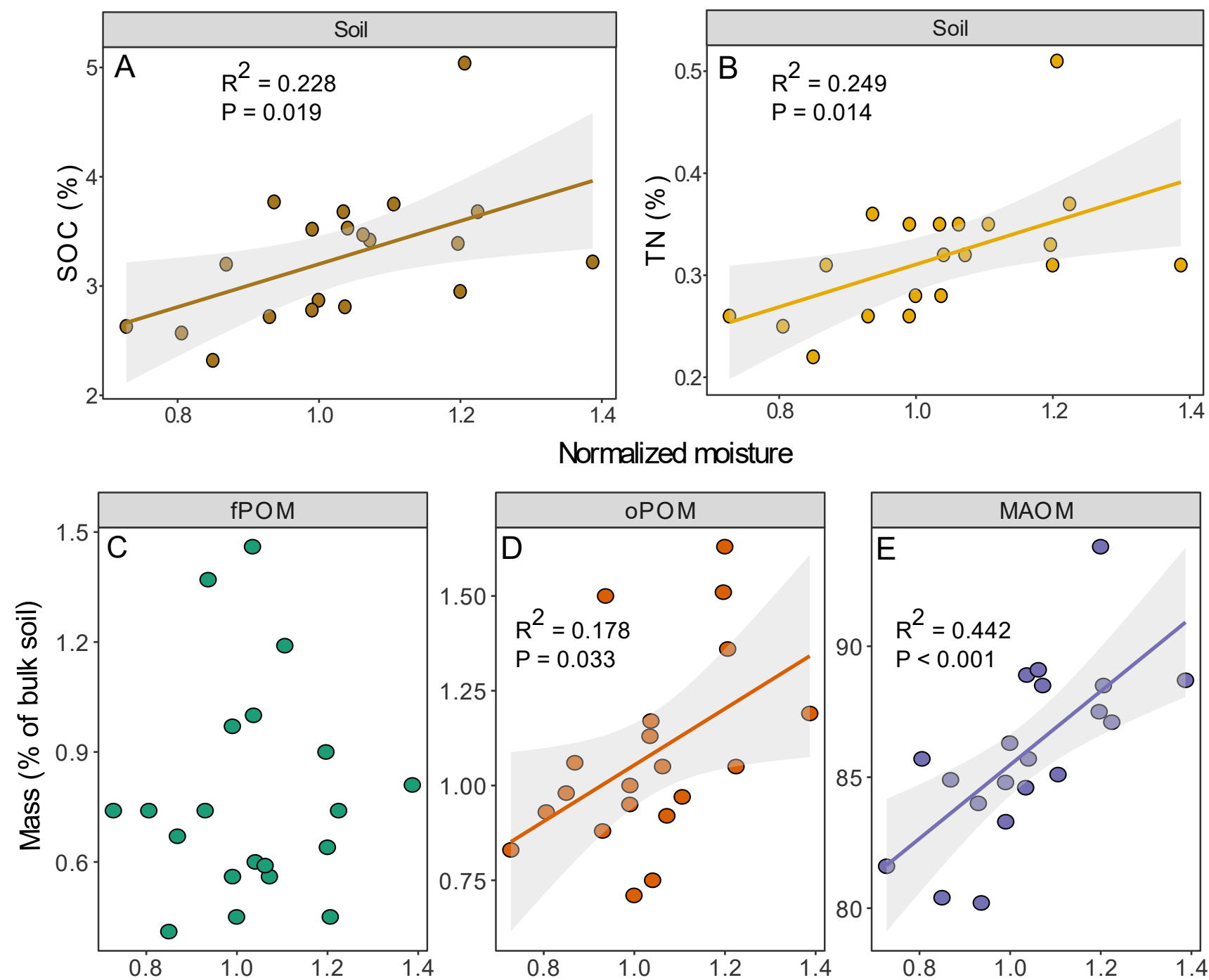

Normalized moisture
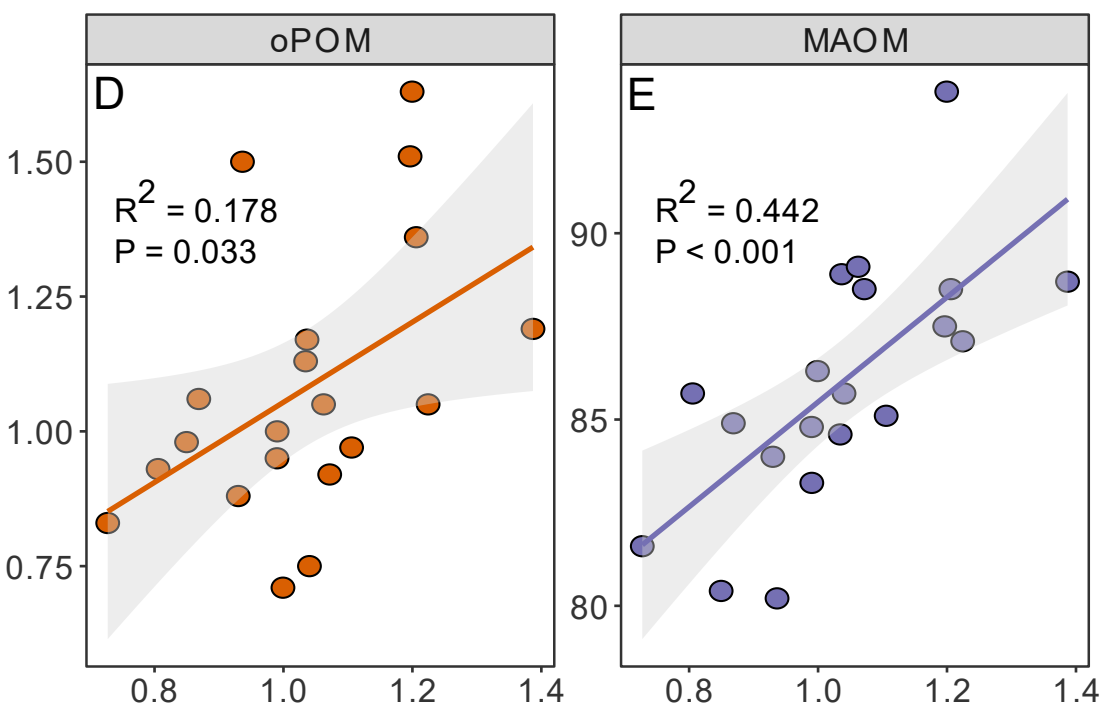

Normalized moisture

282 Figure 1. Contents of soil organic carbon (SOC) (A), total nitrogen (TN) (B), mass percentage of free and occluded particulate organic matter fractions (fPOM and oPOM) (C, D), and mineral associated organic matter (MAOM) fraction (E), as a function of normalized soil moisture values. Lines indicate significant linear regressions $(\mathrm{P}<0.05)$.

\subsection{Microbial biomass}

Microbial biomass $\mathrm{C}$ increased with increasing soil moisture, even when normalized to unit mass

289 SOC $\left(\mathrm{P}<0.0001, \mathrm{R}^{2}=0.564\right)$, while dissolved organic $\mathrm{C}(\mathrm{DOC})$ as a proportion of SOC decreased with

290 increasing soil moisture $\left(\mathrm{R}^{2}=0.23, \mathrm{P}=0.018\right)$ (Figure 2). Overall, DOC and microbial biomass $\mathrm{C}$

291 constituted up to $0.1 \%$ and $1 \%$ of the SOC, respectively. 

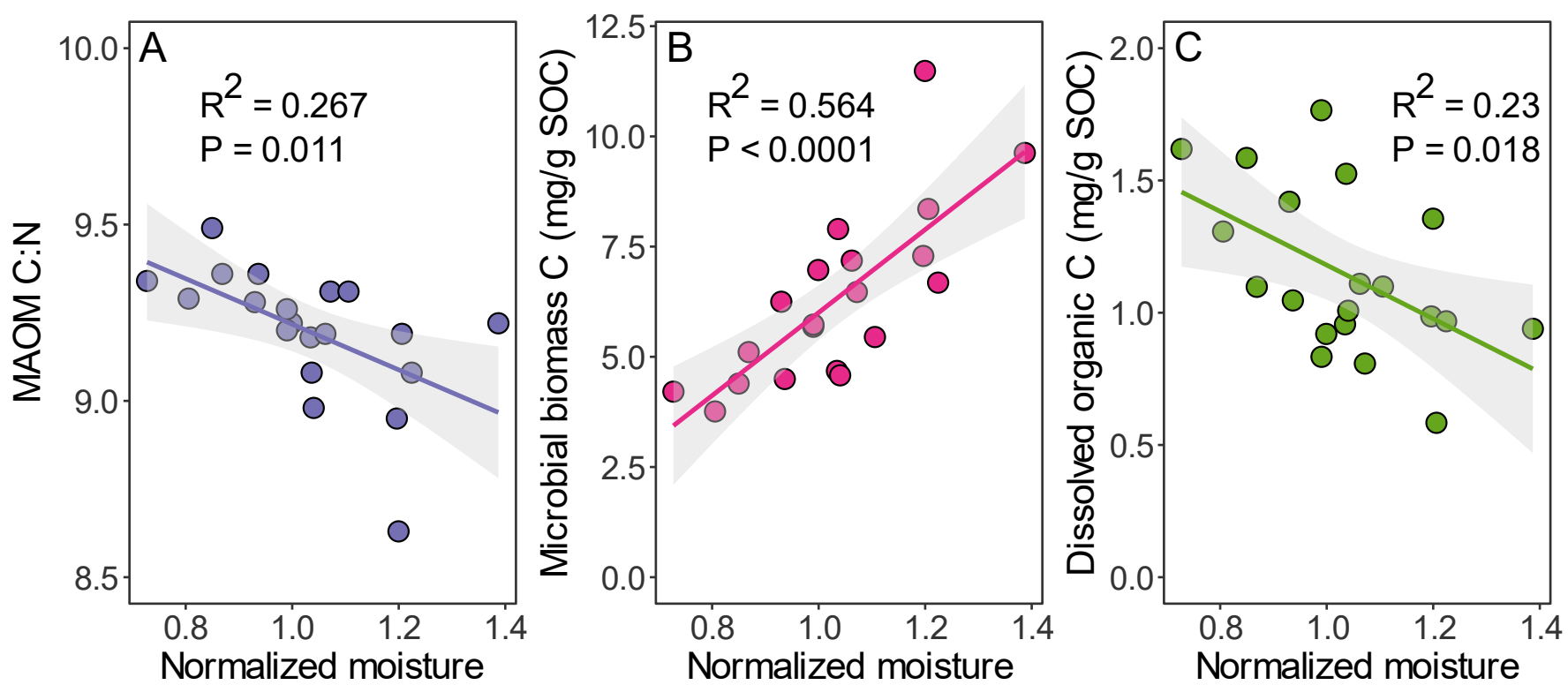

Figure 2. $\mathrm{C}: \mathrm{N}$ ratio of the mineral associated organic matter (MAOM) (A), microbial biomass $\mathrm{C}(\mathrm{B})$ and dissolved organic C (C) (both normalized to SOC content), as a function of normalized soil moisture. Lines indicate significant linear regressions $(\mathrm{P}<0.05)$.

\subsection{Oxide extraction}

The relative concentration of $\mathrm{Al}$ in each extract was similar across normalized soil moisture values

(Figure 3A). However, the relative concentration of Fe in organic-metal complexes (FepY) decreased with increasing normalized soil moisture $\left(\mathrm{R}^{2}=0.33, \mathrm{P}=0.005\right)$ and the relative Fe concentration in crystalline phases $\left(\mathrm{Fe}_{\mathrm{DITH}}\right)$ increased with increasing normalized soil moisture $\left(\mathrm{R}^{2}=0.443, \mathrm{P}=0.001\right)$ (Figure $\left.3 \mathrm{~B}\right)$. In total, the ratio of $\mathrm{Al}$ to $\mathrm{Fe}$ in the $\mathrm{PY}$ and $\mathrm{HH}$ extracts increased with increasing normalized moisture $\left(\mathrm{R}^{2}=\right.$ 0.287, $\mathrm{P}=0.009$ for $\mathrm{PY} ; \mathrm{R}^{2}=0.363, \mathrm{P}=0.003$ for $\mathrm{HH}$ ), but remained similar in the DITH extract (Figure S6). In addition, the concentration of extracted DOC increased as the ratio of $\mathrm{Al} / \mathrm{Fe}$ in the $\mathrm{PY}$ and $\mathrm{HH}$ extracts increased, $\left(\mathrm{R}^{2}=0.26, \mathrm{P}=0.013\right.$ for $\mathrm{PY} ; \mathrm{R}^{2}=0.18, \mathrm{P}=0.035$ for $\left.\mathrm{HH}\right)$ (Figure $\left.3 \mathrm{C}\right)$, indicating that the increase in $\mathrm{Al} / \mathrm{Fe}$ ratio in these extracts with increasing moisture was consistent with increasing DOC. While the distribution of $\mathrm{C}$ across oxide pools varied with normalized moisture, total oxide-associated $\mathrm{C}$ normalized to SOC content (which constituted on average $44 \%$ of the SOC) did not differ across moisture values $(\mathrm{P}=0.79$, Figure $\mathrm{S} 7)$. Linear regression analyses show that extractable Al was better correlated with $\mathrm{DOC}_{\mathrm{PY}}$ and $\mathrm{DOC}_{\mathrm{HH}}$ than $\mathrm{Fe}$. $\mathrm{Al}_{\mathrm{PY}}$ and $\mathrm{Al}_{\mathrm{HH}}$ were significantly and positively correlated to DOC in the 
312 respective extract $\left(\mathrm{R}^{2}=0.513 ; \mathrm{P}=0.0002\right.$, and $\mathrm{R}^{2}=0.411 ; \mathrm{P}=0.0014$ respectively) (Figure 3E) while $\mathrm{Fe}_{\mathrm{PY}}$

313 and $\mathrm{Fe}_{\mathrm{HH}}$ were not significantly correlated to extracted DOC (Figure 3D). Neither Al DITH nor Fe

314 significantly correlated to $\mathrm{DOC}_{\mathrm{DITH}}$.
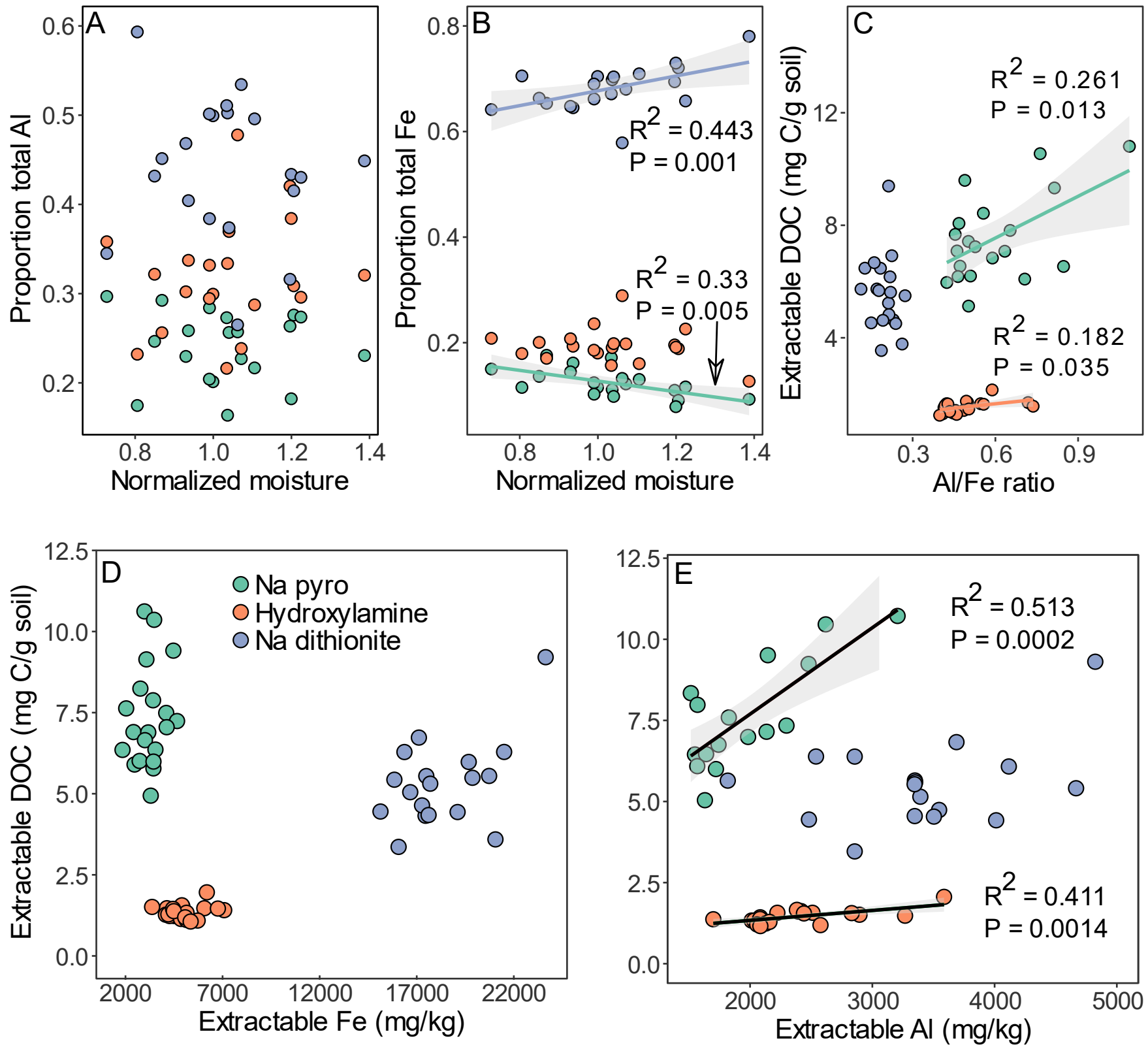

Figure 3. Proportion of total $\mathrm{Al}(\mathrm{A})$, and total $\mathrm{Fe}(\mathrm{B})$, in sodium pyrophosphate, hydroxylamine hydrochloride, and sodium dithionite extracts, as function of normalized soil moisture value. Extractable

318 dissolved organic carbon (DOC) as a function of $\mathrm{Al} / \mathrm{Fe}$ ratio (C), extractable $\mathrm{Fe}(\mathrm{D})$ and $\mathrm{Al}(\mathrm{E})$ in sodium 319 pyrophosphate, hydroxylamine hydrochloride, and sodium dithionite extracts. Lines indicate significant 320 linear regressions $(\mathrm{P}<0.05)$. 


\section{2}

\subsection{ATR-FTIR analysis}

Bulk soil and MAOM spectra feature prominent bands assigned to Si-O stretching vibrations in quartz and clay minerals at 775,795 , and $1000 \mathrm{~cm}^{-1}$, and bands assigned to $\mathrm{O}-\mathrm{H}$ and $\mathrm{N}-\mathrm{H}$ stretching, and clay mineral structural hydroxyl groups at 3390, and $3622 \mathrm{~cm}^{-1}$, respectively (Figure S8). fPOM and oPOM spectra featured $\mathrm{O}-\mathrm{H}$ and $\mathrm{N}-\mathrm{H}$ stretching around the broad band centered at $3350 \mathrm{~cm}^{-1}$ and bands assigned to asymmetric and symmetric stretching of aliphatic $\mathrm{CH}_{2}$ at 2930 and $2855 \mathrm{~cm}^{-1}$. Features originating from organic components (1250-1800 $\mathrm{cm}^{-1}$ ) were less apparent in MAOM and bulk soil spectra (Figure S7). To further investigate how differences in C:N ratios in the MAOM fractions were reflected in SOC composition, spectra of ashed MAOM samples were collected and subtracted from non-ashed MAOM spectra to reveal details of the organic constituents in the MAOM fraction. (Figure 4). The spectra between $1250-1800 \mathrm{~cm}^{-1}$ consisted of bands tentatively assigned to stretching of $\mathrm{C}=\mathrm{O}$ at $1645 \mathrm{~cm}^{-1}, \mathrm{COO}^{-}$and $\mathrm{C}=\mathrm{C}$ at $1600 \mathrm{~cm}^{-1}, \mathrm{C}=\mathrm{N}$ and bending $\mathrm{N}-\mathrm{H}$ vibrations at $1545 \mathrm{~cm}^{-1}$, and $\mathrm{COO}^{-}$at $1420 \mathrm{~cm}^{-1}$. We found higher absorbance in bands assigned to asymmetric and symmetric carboxylate $\mathrm{COO}^{-}$stretch and amide/ketone $\mathrm{C}=\mathrm{O}$ stretch $\left(1420,1600\right.$, and $1645 \mathrm{~cm}^{-1}$, respectively), symmetric $\mathrm{O}-\mathrm{H}$ stretching $\left(3340 \mathrm{~cm}^{-1}\right)$ and asymmetric and symmetric $\mathrm{CH}_{2}$ stretching $\left(2930\right.$ and $2855 \mathrm{~cm}^{-1}$ ) with increasing moisture level. Furthermore, there was a relative increase in the absorbance at $1545 \mathrm{~cm}^{-1}$, assigned to stretching of aromatic $\mathrm{C}=\mathrm{N}$ and bending of $\mathrm{N}-\mathrm{H}$.

\section{$3.4{ }^{13} \mathrm{C}$ NMR analysis}

In the MAOM fraction, the ratio of carboxyl-C/aromatic-C increased with increasing moisture level $\left(R^{2}=0.731 ; P=0.239\right.$, Table $S 3$ ), as measured by ${ }^{13} \mathrm{C}$ NMR (Figure 4 and Figure S9). In addition, the ratio of carboxyl-C/O-alkyl-C and the ratio of O-alkyl-C/alkyl-C in the MAOM fraction increased with increasing moisture level (Table S3). Comparing fractions, carboxyl-C and alkyl-C forms increased, and aromatic-C and O/N-alkyl-C decreased in the MAOM fraction compared to the $\mathrm{POM}$ and oPOM fractions. The composition of bulk soil SOC resembled that of the MAOM fraction, since MAOM contained most of the organic matter. According to the molecular mixing model, this shift echoes higher relative contents of 
347 carbohydrates and char in the fPOM and oPOM fractions in comparison with higher relative contents of 348 proteinaceous and aliphatic compounds in the MAOM fraction and bulk soil (Figure S10).
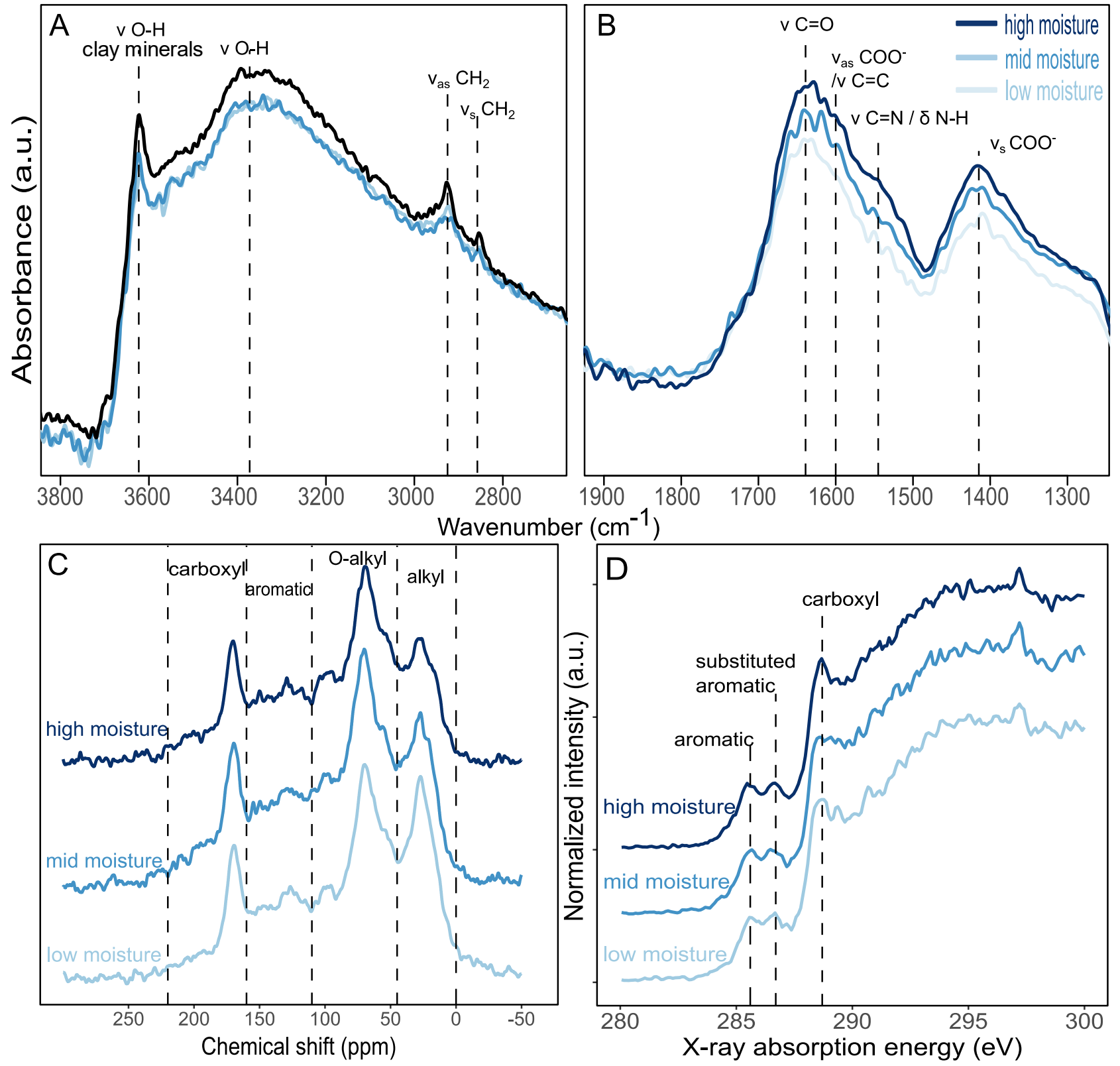

350 Figure 4. Spectroscopic investigation of the chemical composition of mineral associated organic matter

351 (MAOM) fractions from low-, mid-, and high- moisture levels. ATR-FTIR spectra of ashed MAOM

352 fractions $(n=20)$ subtracted from non-ashed MAOM samples $(n=20)$, highlighting the spectral features of

353 SOC and differentiating them from mineral bands. Spectra were averaged across the moisture levels. The

354 information-poor spectral region of $2000-2800 \mathrm{~cm}^{-1}$ is omitted (A and B). ${ }^{13} \mathrm{C}$ NMR spectra of MAOM

355 fractions of composited samples from each moisture level (C). Carbon K-edge near-edge X-ray absorption

356 fine structure (XANES) spectra of MAOM fractions of composited samples from each moisture level (D). 


\section{7} moisture value $(\mathrm{P}=0.68)$.
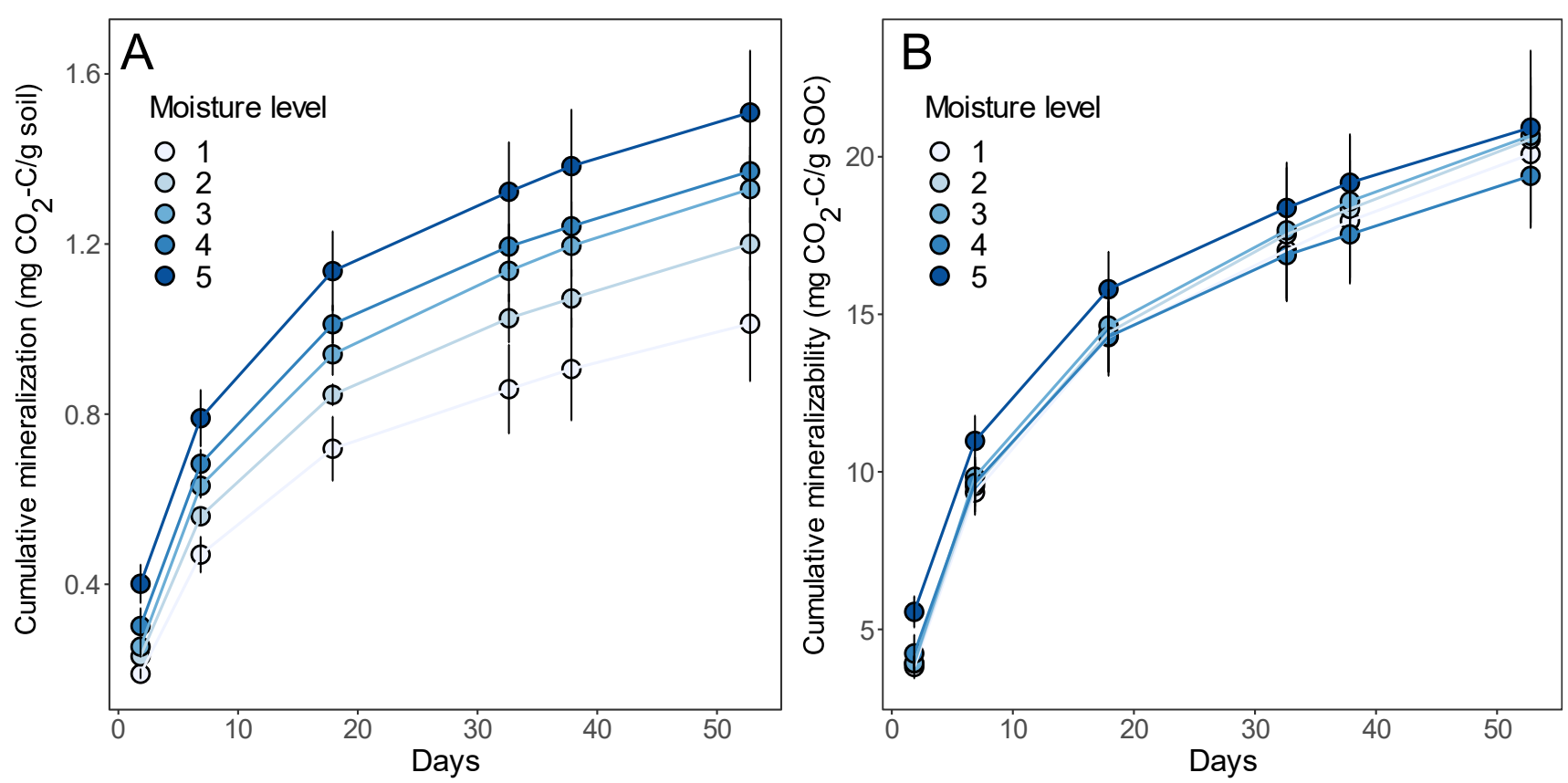

\subsection{Carbon $\mathrm{K}$ - edge NEXAFS analysis}

Confirming the ${ }^{13} \mathrm{C}-\mathrm{NMR}$ results, we found that the ratio carboxyl $\mathrm{C} /$ (aromatic + substituted aromatic C), measured with C NEXAFS (Figure 4D), increased with increasing long term moisture level. We did not evaluate changes in alkyl-C and O-alkyl-C forms since NEXAFS spectra do not have a strong and well-defined feature corresponding to these bonding environments (Heckman et al., 2017). Overall, carboxyl-C forms relatively increased, while aromatic-C forms relatively decreased in the MAOM fraction relative to the $\mathrm{PPOM}$ and $\mathrm{OPOM}$ fractions $\left(\mathrm{R}^{2}=0.866 ; \mathrm{P}=0.166\right.$, Table $\left.\mathrm{S} 3\right)$.

\subsection{SOC mineralization and mineralizability}

Cumulative SOC mineralization and mineralizability after 53 days of incubation are plotted as means and standard errors for each moisture level (Figure 5, Table S1). Mineralization was positively and significantly correlated with normalized moisture values $\left(R^{2}=0.346, P=0.0037\right)$, but no significant relationship was found between SOC mineralizability (mineralization normalized to SOC) and soil

371 Figure 5. Cumulative SOC mineralization (A) and mineralizability (B) over time in soils varying in moisture levels $(n=20)$, plotted as mean and standard error for each moisture level. 
Pearson's correlation coefficients and partial least squares (PLS) regression coefficients for SOC

374 content, mineralization, and mineralizability are presented in Figure 6 and Table 1, respectively. SOC

375 contents were highly positively correlated with $\mathrm{Ca}_{\mathrm{EX}}(\mathrm{r}=0.67), \mathrm{Al} P \mathrm{PY}(\mathrm{r}=0.65), \mathrm{Al} \mathrm{PY}_{\mathrm{P}} / \mathrm{Fe} \mathrm{PY}_{\mathrm{P}}(\mathrm{r}=0.62)$, and

376 normalized moisture $(r=0.52)$, and negatively correlated with DOC $(r=-0.71)$. Similarly, the PLS

377 regression model $\left(\mathrm{R}_{\mathrm{cv}}^{2}=0.449 ; \mathrm{RMSE}_{\mathrm{cv}}=0.439\right)$ identified $\mathrm{Al} \mathrm{PY}_{\mathrm{PY}}, \mathrm{Ca} \mathrm{EX}, \mathrm{Al} \mathrm{PY}_{\mathrm{PY}} / \mathrm{Fe}$ PY, and normalized

378 moisture as positively associated with SOC contents. SOC mineralization was correlated to SOC $(r=0.81)$

379 and $\mathrm{Ca}_{\mathrm{EX}}(\mathrm{r}=0.7)$, and negatively correlated with DOC $(\mathrm{r}=-0.41)$. The PLS model identified SOC and

$380 \mathrm{fPOM}$ as positively associated with SOC mineralization $\left(\mathrm{R}_{\mathrm{cv}}^{2}=0.695 ; \mathrm{RMSE}_{\mathrm{cv}}=0.109\right)$. SOC

381 mineralizability was weakly positively correlated with microbial biomass $C(r=0.39)$, and negatively

382 correlated with $\mathrm{C}: \mathrm{N}(\mathrm{r}=-0.49), \mathrm{Al}_{\mathrm{PY}}(\mathrm{r}=-0.43)$, and FePY $(\mathrm{r}=-0.42)$. Similarly, the PLS model identified

$383 \mathrm{Al}_{\mathrm{py}}, \mathrm{Fe}_{\mathrm{py}}$, and Fe $\mathrm{De}_{\mathrm{DITH}}$ as negatively associated with $\mathrm{SOC}$ mineralizability $\left(\mathrm{R}_{\mathrm{cv}}^{2}=0.033 ; \mathrm{RMSE}_{\mathrm{cv}}=1.864\right)$.

385 Table 1. Results of partial least squares regression models. Coefficients are listed if they are statistically

386 significant at $\mathrm{P}<0.05$, italicized at $\mathrm{P}<0.01$, and bolded at $\mathrm{P}<0.001$. The coefficient of determination of

387 the calibration $\left(\mathrm{R}^{2}\right.$ cal $)$ and cross-validation sets $\left(\mathrm{R}_{\mathrm{cv}}^{2}\right)$, and the root mean of square error (RMSE $\left.E_{\mathrm{CV}}\right)$ are

388 provided.

\begin{tabular}{|c|c|c|c|c|c|c|c|c|c|c|c|}
\hline & Moisture & SOC & Catex & $\mathbf{A l}_{\mathbf{P Y}}$ & Fe $_{P y}$ & $\mathrm{Al}_{\mathrm{PY}} / \mathrm{Fe}_{\mathrm{PY}}$ & $\mathbf{F e}_{\text {DITH }}$ & fPOM & $\mathbf{R}_{\text {cal }}^{2}$ & $\mathbf{R}_{\mathrm{cv}}^{2}$ & $\mathrm{RMSE}_{\mathrm{CV}}$ \\
\hline SOC & 0.204 & -- & 0.266 & 0.255 & -- & 0.244 & -- & -- & 0.601 & 0.449 & 0.439 \\
\hline Mineralization & -- & 0.416 & -- & -- & -- & -- & -- & 0.272 & 0.836 & 0.695 & 0.109 \\
\hline Mineralizability & -- & -- & -- & -0.183 & -0.147 & -- & -0.139 & -- & 0.304 & 0.033 & 1.864 \\
\hline
\end{tabular}




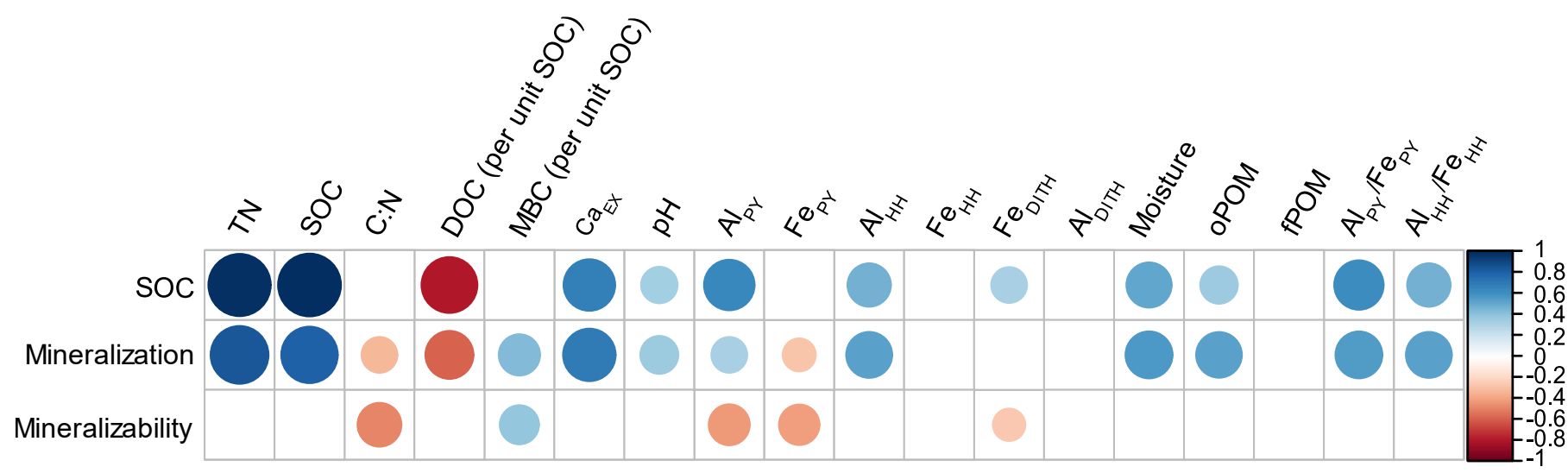

392 Figure 6. Heatmap showing Pearson correlations (r) for selected variables with SOC content, mineralization, and mineralizability. Only significant $(\mathrm{P}<0.05)$ correlations are plotted in the heatmap. The correlations between all variables are reported in Figure S12.

\section{5}

\section{Discussion}

\subsection{Soil organic carbon accrual is unrelated to low microbial activity at high moisture}

We found that SOC and TN increased with increasing long-term soil moisture in the fallow plots investigated in this study (Figure 1). This is consistent with previous work on this experimental site, which reported a similar trend, averaged over several cropping systems (Das et al., 2018). Here, we focused on the fallow plots to eliminate potential effects of the cropping system to allow a direct investigation of the effects of long-term soil moisture on SOC dynamics. Enhanced SOC accumulation can result from higher inputs, lower outputs, or both. Since aboveground biomass, belowground biomass (Das et al., 2018), and the amount of initially decomposing plant litter (Figure 1C) were similar across the moisture gradient, we argue that SOC accumulation resulted from reduced SOC output per unit $\mathrm{C}$ input.

While accumulation of SOC on seasonally saturated soils has been explained in terms of limited mineralization (O’Brien et al., 2010), our evidence suggests that this was not the case here. Measurements indicate that the soil moisture in the wettest sites was lower than $80 \%$ water filled pore space, i.e. less than saturated, in 82\% of the measurements taken over a period of four years, from 2011 to 2014 (Das et al., 2019). A moisture level corresponding to $80 \%$ water filled pore space can be expected to decrease heterotrophic respiration by approximately $10 \%$ from the maximum level (Moyano et al., 2012). Although 
411 we do not have detailed water content data for November through March, the existing data (and our field

412 observations) indicate that soil moisture is the greatest in these winter months. Since SOC mineralization is

413 expected to be the lowest during the winter regardless of water content, saturation-driven limitation on

414 mineralization were likely not important.

415 Furthermore, if limited mineralization at high moisture had been a substantial driver, one might

416 expect an impact on the decomposition trajectory of plant inputs to POM and MAOM fractions, resulting

417 in a greater proportion of SOC remaining in the less processed POM fractions. The increase in oPOM and

418 MAOM amounts with increasing moisture can be attributed to higher contents of silt- and clay-sized

419 particles, and their tendency to aggregate (Fig1). However, our data show that the distribution of C (per

420 unit SOC) among these fractions is similar with regards to long-term moisture (Figure S2), indicating that

421 organic matter mineralization followed a similar (and expected) decomposition trajectory in all the soils

422 studied. We therefore suggest that the principal driver of SOC accumulation were differences in SOC

423 transformation and cycling, which was mediated through microbial metabolism and organo-mineral

424 interactions, and not because of oxygen limitation in transient saturated conditions that coincide with low

425 mineralization during the winter months.

\subsection{High long-term moisture increased microbial conversion of organic inputs into MAOM}

Our results show a strong response of microbial biomass and DOC to differences in long-term soil moisture (Figure 2). Decreasing DOC concentrations and increasing microbial biomass C (per unit SOC) with increasing long-term moisture may have been the result of greater microbial oxidation of DOC, leading to enhanced interactions with minerals surfaces (Lehmann and Kleber, 2015), and ultimately to a decrease in DOC concentration. This hypothesis is supported by decreasing MAOM C:N values with increasing moisture, indicating that they consisted of more processed and oxidized microbial products. Although microbial biomass was measured only once, we assume that this finding reflects a more general trend, as reflected by the different $\mathrm{C}: \mathrm{N}$ ratios of the MAOM fractions. 
Further insights into the chemical composition of MAOM fractions across the moisture gradient was provided by spectroscopic techniques. MAOM fractions from high-moisture soils were enriched in proteinaceous compounds, oxidized carboxylic-C and O-alkyl-C functional groups, and depleted in alkyl-C and aromatic-C functional groups (Figure 4, Table S3, Figure S9, Figure S10). These results indicated that

MAOM of high-moisture soils contained more products of microbial decomposition of aromatic and

440 aliphatic plant residues, with concomitant enrichment in microbial proteinaceous components (Figure S10).

441 The possible role of mineral composition in shaping SOC composition is discussed below. Taken together, 442 our results clearly show that high long-term moisture led to greater oxidation of SOC that explains its 443 accumulation.

\section{4}

\subsection{Long-term moisture shaped mineral composition and $C$ interactions with minerals}

Our results reveal substantial differences in Fe phases across a narrow range of moisture conditions in which reducing conditions are a transient occurrence, and unsaturated conditions predominate. Higher long-term moisture was associated with a 7\% relative decrease in FepY, which comprises organic-Fe complexes and nanocrystalline Fe components (Thompson et al., 2011), and a 10\% relative increase in crystalline Fe that wet-dry cycles, which can induce reducing and oxidizing conditions, may cause reduction of $\mathrm{Fe}$ in non-crystalline phases and subsequent increase in Fe crystallinity (Thompson et al., 2006). Similar observations have been reported for an upland soil experiencing substantial precipitation events (Hodges et al., 2019). Al phases were not affected by moisture (Figure 3A) because they are pH-dependent but not redox-dependent (Bertsch and Bloom, 2018).

Although SOC content has previously been shown to correlate with the amounts of non-crystalline $\mathrm{Fe}$ oxides (Mikutta et al., 2006), surprisingly, DOC extracted from different oxide pools did not significantly correlate with Fe content in each pool (Figure 3D). This suggests that OC contents associated with oxide minerals did not consistently follow the shift in Fe phases along the moisture gradient. However, our results clearly show the increasing importance of $\mathrm{Al}_{\mathrm{PY}}$ and $\mathrm{Al}_{\mathrm{HH}}$ phases for SOC retention with increasing 
460 long-term moisture (Figure 3C, 3D, and 3E). Several recent studies have similarly observed a greater

461 contribution of non-crystalline Al pools for SOC retention, albeit with greater saturation extent and

462 frequency (Possinger et al., 2020) or annual higher precipitation (Inagaki et al., 2020). Solubilization of

$463 \quad \mathrm{FePY}_{\mathrm{PY}} \mathrm{C}$ complexes in high moisture soils and subsequent interaction of $\mathrm{C}$ with $\mathrm{Al}_{\mathrm{PY}}$ and $\mathrm{Al}_{\mathrm{HH}}$, as already

464 appreciated in soils experiencing reducing conditions (Huang and Hall, 2017; Possinger et al., 2020), was

465 likely the reason for the increasing importance of these Al phases in storing SOC. Indeed, a recent analysis

466 of data from 2574 mineral horizons from National Ecological Observatory Network sites across North

467 America showed that oxalate extractable non-crystalline Al was a better predictor of SOC storage than

468 oxalate extractable Fe (Yu et al., 2021), suggesting that this effect was more common than previously

469 thought. Taken together, our results indicate that SOC stabilization by $\mathrm{Al}_{\mathrm{PY}}$ and $\mathrm{Al}_{\mathrm{HH}}$ was directly

470 influenced by long-term moisture levels that are not commonly associated with a loss of FepY.

There is also a possibility (which we did not test) that the chemical composition and mode of

interaction of SOC associated with $\mathrm{Al}$ differs from that of Fe, and that it may vary across soil moisture.

473 Considering the mounting evidence of the critical role of $\mathrm{Al}$ in SOC stabilization at a wide range of

474 moisture conditions, we suggest that future research should seek to understand the composition of SOC

475 associated with non-crystalline $\mathrm{Al}$, and the processes that influence the persistence of this important SOC

476 pool.

Higher long-term moisture was also positively correlated with CaEx and $\mathrm{pH}$ (Figure S12), and in turn

$478 \mathrm{Ca}_{\mathrm{EX}}$ was highly correlated with SOC $(\mathrm{r}=0.67)$, suggesting that increased $\mathrm{Ca}_{\mathrm{EX}}$ in high-moisture soils

479 contributed to SOC accrual. The positive correlations between moisture, $\mathrm{Ca}_{\mathrm{EX}}$, and $\mathrm{pH}$ can be explained by:

480 (1) dissolution of subsoil carbonates and upward migration of $\mathrm{Ca}^{2+}$ ions facilitated by capillary rise in the

481 high moisture soils (Ap horizon soils in this study did not have measurable calcium carbonate contents)

482 (Das et al., 2019), and/or (2) higher contents of clay minerals containing CaEx due to lateral flow and

483 deposition of fine-grained particles in shallower and wetter locations in the field (Das et al., 2018). This 
484 resulted in greater SOC retention in high $\mathrm{Ca}_{\mathrm{EX}}$ soils. Thus, moisture affected SOC accrual through an 485 increase in Ca-bearing fine particles.

\subsection{Long-term moisture regulates SOC accrual through microbial activity and mineral composition}

High long-term soil moisture enhanced microbial oxidation of organic inputs and concomitantly influenced the distribution of oxide mineral phases and content of CaEx-bearing minerals, which in turn interact with the oxidized organic compounds (Figure 6 and Table 1). This complex interaction of soil moisture with biotic and abiotic soil processes was pivotal for SOC accrual in the high moisture soils (Figure 1). These conclusions are consistent with and extend the MEMS framework (Cotrufo et al., 2013) which explains SOC dynamics as an interaction between microbial efficiency for processing organic inputs, and the mineral component capacity to stabilize these processed inputs.

Microbial efficiency can potentially explain the association between long-term soil moisture, microbial biomass, and SOC accrual. High moisture reduces diffusional constraints which could have increased microbial carbon use efficiency (Moyano et al., 2013; Butcher et al., 2020), and resulted in more C taken up by microbes per unit $\mathrm{C}$ input into the soil. Such diffusional constraints may have indeed caused the inverse relationship between long-term moisture and DOC concentration (Figure 2). Our observations suggest that the dependence of carbon use efficiency on soil moisture can result in SOC accrual at field scale. However, more work is needed to understand how to manage soil moisture for optimized carbon use efficiency and increased SOC stocks.

The superposition of microbial activity and an abundance of $\mathrm{Ca}_{\mathrm{EX}}$ acted to enrich high moisture MAOM fractions in carboxylate-rich compounds. The contribution of Ca $\mathrm{aX}_{\mathrm{EX}}$ for SOC content and the prevalence of carboxylic C in MAOM fractions (Figure 4, Table S3, Figure S10) indicate that clay-Ca$\mathrm{COO}^{-}$interactions were an important mechanism for SOC protection in the high moisture soils (Mouvenchery et al., 2012; Chen et al., 2014; Rowley et al., 2018; Wan et al., 2021). These interactions are expected to prevail in the higher $\mathrm{pH}$ values found in the high-moisture soils which, since high $\mathrm{pH}$ promotes electrostatic interactions between Caex and carboxylates (Rowley et al., 2020). The insignificant 
510 correlation between MAOM and SOC contents indicate that specific effects of CaEx, rather than greater

511 contents of silt- and clay-sized particles, played a role (Table 1, Figure 6, and Figure S12). As highlighted

512 recently, mineralogical composition is a better predictor than particle size distribution for SOC content

513 (Khomo et al., 2017; Rasmussen et al., 2018; Singh et al., 2018). While it has been suggested that Ca and

514 non-crystalline Fe can form ternary structures with carboxylate groups (Sowers et al., 2018), our soils

515 showed a negative correlation between $\mathrm{Fe}_{\mathrm{PY}}$ and $\mathrm{Ca}_{\mathrm{Ex}}$ (Figure S12), implying that ternary Ca-Fe-C

516 structures were less important for SOC accrual in our study. Long-term moisture also increased the role of

517 Al in SOC storage (Figure 6, Table 1). As non-crystalline Fe was reduced under transient saturation events 518 and leached out of the surface soils, the importance of non-crystalline $\mathrm{Al}$ phases for storing $\mathrm{C}$ increased

519 (Figure 3C), even at a lower moisture range in comparison to other studies (Inagaki et al., 2020; Possinger

520 et al., 2020). The composition of compounds that preferentially adsorb to non-crystalline $\mathrm{Al}$ and Al-organic 521 complexes is still unclear, but the available information on podzolic soils suggests that AlPy may interact 522 with carboxylate-rich compounds (Parfitt et al., 1999; Possinger et al., 2020).

\section{5. Conclusions}

In the trade-off between mineralization and accrual, high long-term moisture increased SOC accrual, even at a range of soil moisture not expected to constrain decomposition or alter soil oxide mineral composition, indicating that such changes are likely to occur even along moderate soil moisture gradients.

The direction and magnitude of changes to SOC stocks under changing long-term soil moisture are likely to be dependent on additional soil properties that affect microbial conversion of organic inputs and mineral interaction of these products. For example, soils which do not have the mineral capacity to interact with oxidized organic compounds may not benefit from increases to moisture. Climate change is not only changing soil moisture, but critically, also altering the magnitude and temporal patterns of moisture variability through extreme floods and drought. The relative roles of mean long-term moisture vs. moisture temporal variability on stabilization mechanisms are still not clear. Currently, conventional C models consider soil moisture as a physical variable only, and models that account for microbial traits do not 
535 include the potential effect of moisture on carbon use efficiency. These processes will have to be clarified 536 to maintain SOC stocks by driving forward stabilization of organic inputs.

\section{6. Acknowledgements}

This research was supported by BARD, the United States - Israel Binational Agricultural Research and Development Fund, Vaadia-BARD Postdoctoral Fellowship Award No. FI-573-2018, and the U.S.

540 Department of Energy, Office of Biological \& Environmental Research Genomic Science Program Award $541 \quad$ No. DE-SC0016364.

\section{2}

\section{References}

Berg A. and Sheffield J. (2018) Climate Change and Drought: the Soil Moisture Perspective. Curr. Clim. Chang. Reports 4, 180-191. Available at: https://link.springer.com/article/10.1007/s40641-018-00950 [Accessed July 13, 2021].

Bertsch P. M. and Bloom P. R. (2018) Aluminum. Methods Soil Anal. Part 3 Chem. Methods, 517-550.

Butcher K. R., Nasto M. K., Norton J. M. and Stark J. M. (2020) Physical mechanisms for soil moisture effects on microbial carbon-use efficiency in a sandy loam soil in the western United States. Soil Biol. Biochem. 150, 107969.

Chen C., Dynes J. J., Wang J., Karunakaran C. and Sparks D. L. (2014) Soft X-ray spectromicroscopy study of mineral-organic matter associations in pasture soil clay fractions. Environ. Sci. Technol. $\mathbf{4 8}$, 6678-6686. Available at: http://pubs.acs.org/doi/pdf/10.1021/es405485a.

Chen Q., Niu B., Hu Y., Luo T. and Zhang G. (2020) Warming and increased precipitation indirectly affect the composition and turnover of labile-fraction soil organic matter by directly affecting vegetation and microorganisms. Sci. Total Environ. 714, 136787.

Cotrufo M. F., Wallenstein M. D., Boot C. M., Denef K. and Paul E. (2013) The Microbial EfficiencyMatrix Stabilization (MEMS) framework integrates plant litter decomposition with soil organic matter stabilization: Do labile plant inputs form stable soil organic matter? Glob. Chang. Biol. 19, 988-995. 
559 Courchesne F. and Turmel M. C. (2007) Extractable Al, Fe, Mn, and Si. In Soil Sampling and Methods of Analysis (eds. M. R. Carter and E. G. Gregorich). CRC Press. pp. 335-344.

561 Das S., Richards B. K., Hanley K. L., Krounbi L., Walter M. F., Walter M. T., Steenhuis T. S. and

DeCiucies S., Whitman T., Woolf D., Enders A. and Lehmann J. (2018) Priming mechanisms with additions of pyrogenic organic matter to soil. Geochim. Cosmochim. Acta 238, 329-342.

Doetterl S., Stevens A., Six J., Merckx R., Van Oost K., Casanova Pinto M., Casanova-Katny A., Muñoz C., Boudin M., Zagal Venegas E. and Boeckx P. (2015) Soil carbon storage controlled by interactions between geochemistry and climate. Nat. Geosci. 8, 780-783.

Falloon P., Jones C. D., Ades M. and Paul K. (2011) Direct soil moisture controls of future global soil carbon changes: An important source of uncertainty. Global Biogeochem. Cycles 25.

Fine A. K., Schmidt M. P. and Martínez C. E. (2018) Nitrogen-rich compounds constitute an increasing proportion of organic matter with depth in Oi-Oe-Oa-A horizons of temperate forests. Geoderma 323, 1-12. Available at: https://doi.org/10.1016/j.geoderma.2018.02.039.

Friedlingstein P., Jones M. W., O’Sullivan M., Andrew R. M., Hauck J., Peters G. P., Peters W., Pongratz J., Sitch S., Le Quéré C., Bakker D. C. E., Canadell J. G., Ciais P., Jackson R. B., Anthoni P., Barbero L., Bastos A., Bastrikov V., Becker M., Bopp L., Buitenhuis E., Chandra N., Chevallier F., Chini L. P., Currie K. I., Feely R. A., Gehlen M., Gilfillan D., Gkritzalis T., Goll D. S., Gruber N., Gutekunst S., Harris I., Haverd V., Houghton R. A., Hurtt G., Ilyina T., Jain A. K., Joetzjer E., Kaplan J. O., Kato E., Klein Goldewijk K., Korsbakken J. I., Landschützer P., Lauvset S. K., Lefèvre N., Lenton A., Lienert S., Lombardozzi D., Marland G., McGuire P. C., Melton J. R., Metzl N., Munro D. R., Nabel 
J. E. M. S., Nakaoka S.-I., Neill C., Omar A. M., Ono T., Peregon A., Pierrot D., Poulter B., Rehder G., Resplandy L., Robertson E., Rödenbeck C., Séférian R., Schwinger J., Smith N., Tans P. P., Tian H., Tilbrook B., Tubiello F. N., van der Werf G. R., Wiltshire A. J. and Zaehle S. (2019) Global Carbon Budget 2019. Earth Syst. Sci. Data 11, 1783-1838. Available at: https://doi.org/10.5194/essd11-1783-2019.

Ghezzehei T. A., Sulman B., Arnold C. L., Bogie N. A. and Asefaw Berhe A. (2019) On the role of soil water retention characteristic on aerobic microbial respiration. Biogeosciences 16, 1187-1209.

Grillakis M. G. (2019) Increase in severe and extreme soil moisture droughts for Europe under climate change. Sci. Total Environ. 660, 1245-1255.

Hall S. J., Berhe A. A. and Thompson A. (2018) Order from disorder: do soil organic matter composition and turnover co-vary with iron phase crystallinity? Biogeochemistry 140, 93-110. Available at: https://doi.org/10.1007/s10533-018-0476-4.

Heckman K., Lawrence C. R. and Harden J. W. (2018) A sequential selective dissolution method to quantify storage and stability of organic carbon associated with $\mathrm{Al}$ and Fe hydroxide phases. Geoderma 312, 24-35. Available at: http://dx.doi.org/10.1016/j.geoderma.2017.09.043.

Heckman K., Torres D., Swanston C. and Lehmann J. (2017) Carbon and nitrogen molecular composition of soil organic matter fractions resistant to oxidation. Soil Res. 55, 809-818.

Heymann K., Lehmann J., Solomon D., Schmidt M. W. I., Regier T., Lehmann Johannes J., Solomon D., Schmidt M. W. I. and Regier T. (2011) C 1s K-edge near edge X-ray absorption fine structure (NEXAFS) spectroscopy for characterizing functional group chemistry of black carbon. Org. Geochem. 42, 1055-1064. Available at: http://www.sciencedirect.com/science/article/pii/S0146638011001781.

Hodges C., Mallard J., Markewitz D., Barcellos D. and Thompson A. (2019) Seasonal and spatial variation in the potential for iron reduction in soils of the Southeastern Piedmont of the US. Catena 180, 32-40. Available at: https://doi.org/10.1016/j.catena.2019.03.026. 
609 Huang W. and Hall S. J. (2017) Elevated moisture stimulates carbon loss from mineral soils by releasing $610 \quad$ protected organic matter. Nat. Commun. 8.

611 Inagaki T. M., Possinger A. R., Grant K. E., Schweizer S. A., Mueller C. W., Derry L. A., Lehmann J. and

$$
\text { Kögel-Knabner I. (2020) Subsoil organo-mineral associations under contrasting climate conditions. }
$$
Geochim. Cosmochim. Acta 270, 244-263.

Kaiser K. and Zech W. (1996) Defects in Estimation of Aluminum in Humus Complexes of Podzolic Soils by Pyrophosphate Extraction. Soil Sci. 161.

Khomo L., Trumbore S., Bern C. R. and Chadwick O. A. (2017) Timescales of carbon turnover in soils with mixed crystalline mineralogies. Soil 3, 17-30.

Kleber M., Bourg I. C., Coward E. K., Hansel C. M., Myneni S. C. B. and Nunan N. (2021) Dynamic interactions at the mineral-organic matter interface. Nat. Rev. Earth Environ. 0123456789, 1-19. Available at: http://dx.doi.org/10.1038/s43017-021-00162-y.

Knicker H. and Lüdemann H. D. (1995) N-15 and C-13 CPMAS and solution NMR studies of N-15 enriched plant material during 600 days of microbial degradation. Org. Geochem. 23, 329-341.

Kramer M. G. and Chadwick O. A. (2018) Climate-driven thresholds in reactive mineral retention of soil carbon at the global scale. Nat. Clim. Chang. 8, 1104-1108. Available at: http://dx.doi.org/10.1038/s41558-018-0341-4.

Kramer M. G., Sanderman J., Chadwick O. A., Chorover J. and Vitousek P. M. (2012) Long-term carbon storage through retention of dissolved aromatic acids by reactive particles in soil. Glob. Chang. Biol. 18, 2594-2605.

Lehmann J., Kinyangi J. and Solomon D. (2007) Organic matter stabilization in soil microaggregates: Implications from spatial heterogeneity of organic carbon contents and carbon forms. Biogeochemistry 85, 45-57. Available at: http://www.css.cornell.edu/faculty/lehmann/publ/Biogeochemistry.

Lehmann J. and Kleber M. (2015) The contentious nature of soil organic matter. Nature 528, 60-68.

Masiello C. A., Chadwick O. A., Southon J., Torn M. S. and Harden J. W. (2004) Weathering controls on 
mechanisms of carbon storage in grassland soils. Global Biogeochem. Cycles 18, 1-9.

635

Mikutta R., Kleber M., Torn M. S. and Jahn R. (2006) Stabilization of soil organic matter: Association with minerals or chemical recalcitrance? Biogeochemistry 77, 25-56. Available at: http://link.springer.com/10.1007/s10533-005-0712-6.

Mikutta R., Schaumann G. E., Gildemeister D., Bonneville S., Kramer M. G., Chorover J., Chadwick O. A. and Guggenberger G. (2009) Biogeochemistry of mineral-organic associations across a long-term mineralogical soil gradient (0.3-4100kyr), Hawaiian Islands. Geochim. Cosmochim. Acta 73, 20342060.

Minasny B., Malone B. P., McBratney A. B., Angers D. A., Arrouays D., Chambers A., Chaplot V., Chen Z., Cheng K., Das B. S., Field D. J., Gimona A., Hedley C. B., Hong S. Y., Mandal B., Marchant B. P., Martin M., McConkey B. G., Mulder V. L., O’Rourke S., Richer-de-Forges A. C., Odeh I., Padarian J., Paustian K., Pan G., Poggio L., Savin I., Stolbovoy V., Stockmann U., Sulaeman Y., Tsui C., Vågen T., van Wesemael B. and Winowiecki L. (2017) Soil carbon 4 per mille. Geoderma 292, 59-86. Available at: http://dx.doi.org/10.1016/j.geoderma.2017.01.002.

Mouvenchery Y. K., Diehl D. and Schaumann G. E. (2012) Cation-mediated cross-linking in natural organic matter : a review. , 41-54.

Moyano F. E., Manzoni S. and Chenu C. (2013) Responses of soil heterotrophic respiration to moisture availability: An exploration of processes and models. Soil Biol. Biochem. 59, 72-85.

Moyano F. E., Vasilyeva N., Bouckaert L., Cook F., Craine J., Curiel Yuste J., Don A., Epron D., Formanek P., Franzluebbers A., Ilstedt U., Kätterer T., Orchard V., Reichstein M., Rey A., Ruamps L., Subke J. A., Thomsen I. K. and Chenu C. (2012) The moisture response of soil heterotrophic respiration: Interaction with soil properties. Biogeosciences 9, 1173-1182.

Nelson P. N. and Baldock J. A. (2005) Estimating the molecular composition of a diverse range of natural organic materials from solid-state 13C NMR and elemental analyses. Biogeochemistry 72, 1-34.

O’Brien S. L., Jastrow J. D., Grimley D. A. and Gonzalez-Meler M. A. (2010) Moisture and vegetation 
controls on decadal-scale accrual of soil organic carbon and total nitrogen in restored grasslands. Glob. Chang. Biol. 16, 2573-2588.

Parfitt R. L. and Childs C. W. (1988) Estimation of forms of fe and al: A review, and analysis of contrasting soils by dissolution and moessbauer methods. Aust. J. Soil Res. 26, 121-144.

Parfitt R. L., Yuan G. and Theng B. K. G. (1999) A 13C-NMR study of the interactions of soil organic matter with aluminium and allophane in podzols. Eur. J. Soil Sci. 50, 695-700. Available at: https://onlinelibrary.wiley.com/doi/full/10.1046/j.1365-2389.1999.00274.x [Accessed May 25, 2021].

Parikh S. J., Goyne K. W., Margenot A. J., Mukome F. N. D. D. and Calderón F. J. (2014) Soil chemical insights provided through vibrational spectroscopy. Adv. Agron. 126, 1-148.

Porras R. C., Hicks Pries C. E., McFarlane K. J., Hanson P. J. and Torn M. S. (2017) Association with pedogenic iron and aluminum: effects on soil organic carbon storage and stability in four temperate forest soils. Biogeochemistry 133, 333-345.

Possinger A. R., Bailey S. W., Inagaki T. M., Kögel-Knabner I., Dynes J. J., Arthur Z. A. and Lehmann J. (2020) Organo-mineral interactions and soil carbon mineralizability with variable saturation cycle frequency. Geoderma 375.

Rasmussen C., Heckman K., Wieder W. R., Keiluweit M., Lawrence C. R., Berhe A. A., Blankinship J. C., Crow S. E., Druhan J. L., Hicks Pries C. E., Marin-Spiotta E., Plante A. F., Schädel C., Schimel J. P., Sierra C. A., Thompson A. and Wagai R. (2018) Beyond clay: towards an improved set of variables for predicting soil organic matter content. Biogeochemistry 137, 297-306.

Ravel B. and Newville M. (2005) ATHENA, ARTEMIS , HEPHAESTUS : data analysis for X-ray absorption spectroscopy using IFEFFIT. J. Synchrotron Radiat. 12, 537-541. Available at: https://doi.org/10.1107/S0909049505012719.

Ross G. J., Wang C. and Schuppli P. A. (1985) Hydroxylamine and Ammonium Oxalate Solutions as Extractants for Iron and Aluminum from Soils. Soil Sci. Soc. Am. J. 49, 783-785.

Rowley M. C., Grand S., Adatte T. and Verrecchia E. P. (2020) A cascading influence of calcium 
carbonate on the biogeochemistry and pedogenic trajectories of subalpine soils, Switzerland. Geoderma 361, 114065. Available at: https://doi.org/10.1016/j.geoderma.2019.114065.

Rowley M. C., Grand S. and Verrecchia É. P. (2018) Calcium-mediated stabilisation of soil organic carbon. Biogeochemistry 137, 27-49.

Sanderman J., Maddern T. and Baldock J. (2014) Similar composition but differential stability of mineral retained organic matter across four classes of clay minerals. Biogeochemistry 121, 409-424.

Scharlemann J. P., Tanner E. V., Hiederer R. and Kapos V. (2014) Global soil carbon: Understanding and managing the largest terrestrial carbon pool. Carbon Manag. 5, 81-91. Available at: https://www.tandfonline.com/doi/abs/10.4155/cmt.13.77 [Accessed July 13, 2021].

Schjønning P., Thomsen I. K., Moldrup P. and Christensen B. T. (2003) Linking Soil Microbial Activity to Water- and Air-Phase Contents and Diffusivities. Soil Sci. Soc. Am. J. 67, 156-165. Available at: https://acsess.onlinelibrary.wiley.com/doi/full/10.2136/sssaj2003.1560 [Accessed July 13, 2021].

Schurig C., Smittenberg R. H., Berger J., Kraft F., Woche S. K., Goebel M. O., Heipieper H. J., Miltner A. and Kaestner M. (2013) Microbial cell-envelope fragments and the formation of soil organic matter: A case study from a glacier forefield. Biogeochemistry 113, 595-612.

Seneviratne S. I., Corti T., Davin E. L., Hirschi M., Jaeger E. B., Lehner I., Orlowsky B. and Teuling A. J. (2010) Investigating soil moisture-climate interactions in a changing climate: A review. Earth-Science Rev. 99, 125-161.

Singh M., Sarkar B., Sarkar S., Churchman J., Bolan N., Mandal S., Menon M., Purakayastha T. J. and Beerling D. J. (2018) Stabilization of Soil Organic Carbon as Influenced by Clay Mineralogy. 1st ed., Elsevier Inc. Available at: http://dx.doi.org/10.1016/bs.agron.2017.11.001.

Solomon D., Lehmann J., Kinyangi J., Liang B., Heymann K., Dathe L., Hanley K., Wirick S. and Jacobsen C. (2009) Carbon (1s) NEXAFS Spectroscopy of Biogeochemically Relevant Reference Organic Compounds. Soil Sci. Soc. Am. J. 73, 1817. Available at: https://www.soils.org/publications/sssaj/abstracts/73/6/1817. 
Soong J. L., Castanha C., Hicks Pries C. E., Ofiti N., Porras R. C., Riley W. J., Schmidt M. W. I. and Torn M. S. (2021) Five years of whole-soil warming led to loss of subsoil carbon stocks and increased CO2 efflux. Sci. Adv. 7, 1-9.

Thompson A., Chadwick O. A., Rancourt D. G. and Chorover J. (2006) Iron-oxide crystallinity increases during soil redox oscillations. Geochim. Cosmochim. Acta 70, 1710-1727.

Thompson A., Rancourt D. G., Chadwick O. A. and Chorover J. (2011) Iron solid-phase differentiation along a redox gradient in basaltic soils. Geochim. Cosmochim. Acta 75, 119-133. Available at: http://dx.doi.org/10.1016/j.gca.2010.10.005.

Todd-Brown K. E. O., Randerson J. T., Hopkins F., Arora V., Hajima T., Jones C., Shevliakova E., Tjiputra J., Volodin E., Wu T., Zhang Q. and Allison S. D. (2014) Changes in soil organic carbon storage predicted by Earth system models during the 21st century. Biogeosciences 11, 2341-2356.

Wagai R., Kajiura M. and Asano M. (2020) Iron and aluminum association with microbially processed organic matter via meso-density aggregate formation across soils: Organo-metallic glue hypothesis. Soil 6, 597-627.

Wagai R. and Mayer L. M. (2007) Sorptive stabilization of organic matter in soils by hydrous iron oxides. 71, 25-35.

Wan D., Ma M., Peng N., Luo X., Chen W., Cai P., Wu L., Pan H., Chen J., Yu G. and Huang Q. (2021) Effects of long-term fertilization on calcium-associated soil organic carbon: Implications for C sequestration in agricultural soils. Sci. Total Environ. 772, 145037. Available at: https://doi.org/10.1016/j.scitotenv.2021.145037.

Witt C., Gaunt J. L., Galicia C. C., Ottow J. C. G. and Neue H. U. (2000) A rapid chloroform-fumigation extraction method for measuring soil microbial biomass carbon and nitrogen in flooded rice soils. Biol. Fertil. Soils 30, 510-519.

Wojdyr M. (2010) Fityk : a general-purpose peak fitting program. J. Appl. Crystallogr. 43, 1126-1128. Available at: https://doi.org/10.1107/S0021889810030499. 
This is a preprint submitted to Earth ArXiv and has not been peer reviewed

734 Yu W., Weintraub S. R. and Hall S. J. (2021) Climatic and Geochemical Controls on Soil Carbon at the 735 Continental Scale: Interactions and Thresholds. Global Biogeochem. Cycles 35, 1-15.

736 Zhu X., Jackson R. D., DeLucia E. H., Tiedje J. M. and Liang C. (2020) The soil microbial carbon pump: 737 From conceptual insights to empirical assessments. Glob. Chang. Biol. 26, 6032-6039. 738 


\section{Supplementary Material for}

\section{Higher Long-Term Soil Moisture Increases Organic Carbon Accrual Through Microbial Conversion of Organic Inputs}

Itamar A. Shabtai ${ }^{1}, *$, Srabani Das ${ }^{2}$, Thiago M. Inagaki ${ }^{3}$, Behrooz Azimzadeh ${ }^{1}$, Brian Richards ${ }^{4}$, Carmen Enid Martínez ${ }^{1}$, Ingrid Kögel-Knabner ${ }^{3,6}$, and Johannes Lehmann ${ }^{1,5}$

*Corresponding author

${ }^{1}$ Soil and Crop Sciences, School of Integrative Plant Science, Cornell University, Ithaca, NY, 14850,

${ }^{2}$ Center for Carbon Management and Sequestration, The Ohio State University, Columbus, OH, 43210, USA

${ }^{3}$ Chair of Soil Science, School of Life Sciences, Technical University of Munich, 85354 Freising,

Germany

${ }^{4}$ Biological and Environmental Engineering, Cornell University, Ithaca, NY, 14850, USA

${ }^{5}$ Cornell Atkinson Center for Sustainability, Cornell University, Ithaca, NY, 14850, USA

${ }^{6}$ Institute for Advanced Study, Technical University of Munich, Lichtenbergstraße 2a, 85748 
This is a preprint submitted to Earth ArXiv and has not been peer reviewed

754 Table S1. Categorical moisture levels and normalized moisture values of the studied soils $(n=20)$.

\begin{tabular}{|c|c|c|c|}
\hline Plot & Subplot & Moisture level [Q1=driest] & Normalized moisture value \\
\hline \multirow[t]{5}{*}{ A } & 1 & Q3 & 1.037 \\
\hline & 2 & Q5 & 1.387 \\
\hline & 3 & Q2 & 1.034 \\
\hline & 4 & Q4 & 1.196 \\
\hline & 5 & Q1 & 0.936 \\
\hline \multirow[t]{5}{*}{$\mathrm{F}$} & 1 & Q1 & 0.869 \\
\hline & 2 & Q3 & 1.072 \\
\hline & 3 & Q5 & 1.206 \\
\hline & 4 & Q2 & 0.999 \\
\hline & 5 & Q4 & 1.106 \\
\hline \multirow[t]{5}{*}{ I } & 1 & Q2 & 0.850 \\
\hline & 2 & Q3 & 1.040 \\
\hline & 3 & Q4 & 1.062 \\
\hline & 4 & Q5 & 1.200 \\
\hline & 5 & Q1 & 0.727 \\
\hline \multirow[t]{5}{*}{$\mathrm{P}$} & 1 & Q3 & 0.990 \\
\hline & 2 & Q4 & 0.990 \\
\hline & 3 & Q5 & 1.224 \\
\hline & 4 & Q2 & 0.930 \\
\hline & 5 & Q1 & 0.805 \\
\hline
\end{tabular}


Table S2. Results from elemental and isotope characterization of plant biomass and soil density fractions. The average value is followed by the standard deviation $( \pm$ S.D.) in parentheses. The level of significant from the 2-way ANOVA model of fraction and moisture is reported as *** $P<0.001$, or non-significant $(n s)$.

\begin{tabular}{lccc}
\hline Soil fraction/biomass & $\mathrm{C}: \mathrm{N}$ & $\delta^{13} \mathrm{C}(\%)$ & $\delta^{15} \mathrm{~N}(\%)$ \\
\hline Roots & $50.21(7.5)$ & $-28.62(0.5)$ & $3.50(1.2)$ \\
Shoots & $38.86(6.1)$ & $-28.11(0.3)$ & $1.97(1.2)$ \\
fPOM & $29.97(3.0)$ & $-28.37(0.5)$ & $4.39(1.9)$ \\
oPOM & $22.88(2.2)$ & $-28.80(0.4)$ & $3.81(1.4)$ \\
MAOM & $9.20(0.19)$ & $-27.35(0.3)$ & $5.29(0.7)$ \\
Bulk soil & $10.31(0.4)$ & $-27.53(0.3)$ & $5.82(3.2)$ \\
\hline
\end{tabular}

Source of variance

Fraction $* * *$

Moisture ns

Fraction*Moisture

ns

$\begin{array}{cc}* * * & * * * \\ * * * & \mathrm{~ns} \\ \mathrm{~ns} & \mathrm{~ns}\end{array}$

Table S3. ${ }^{13} C$-NMR integral ratios and C-NEXAFS peak height ratios of MAOM fractions from composited samples of low, mid, and high moisture levels.

\begin{tabular}{lcccc}
\hline Moisture level & \multicolumn{2}{c}{ carboxyl-C/aromatic-C } & carboxyl/O-alkyl-C & O-alkyl-C/alkyl-C \\
\hline & C-NEXAFS & ${ }^{13}$ C-NMR & ${ }^{13}$ C-NMR & ${ }^{13}$ C-NMR \\
Low & 1.349 & 0.533 & 0.262 & 1.454 \\
Mid & 1.363 & 0.594 & 0.286 & 1.928 \\
High & 1.429 & 0.615 & 0.290 & 2.063 \\
\hline
\end{tabular}




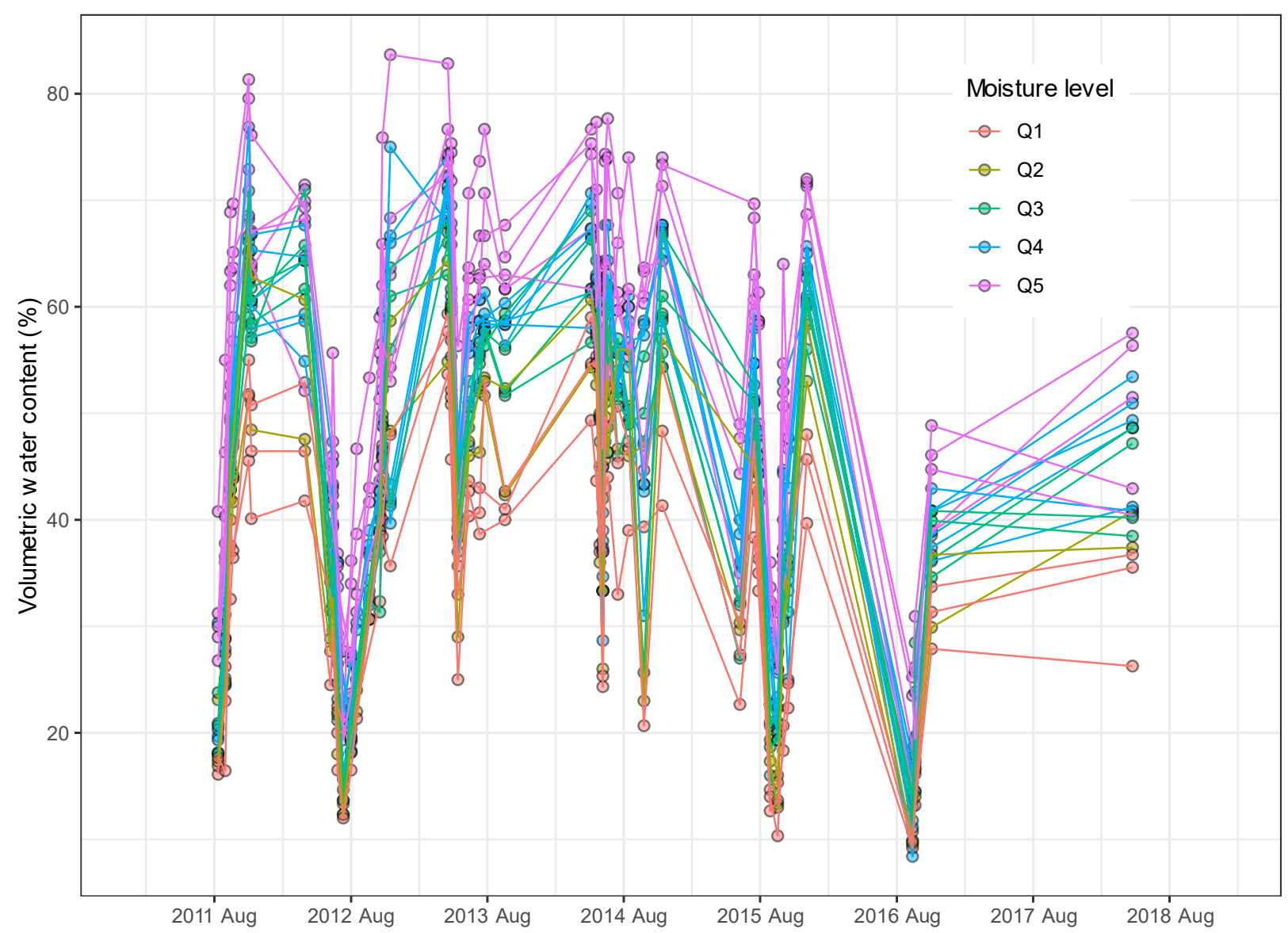

$76 i$

768 Figure S1. Soil volumetric water content from 2011 to 2018. Each data point represents a mean of time 769 domain reflectometry (TDR) measurements $(n=3)$. Data from Das et al. (2019) 
This is a preprint submitted to Earth ArXiv and has not been peer reviewed
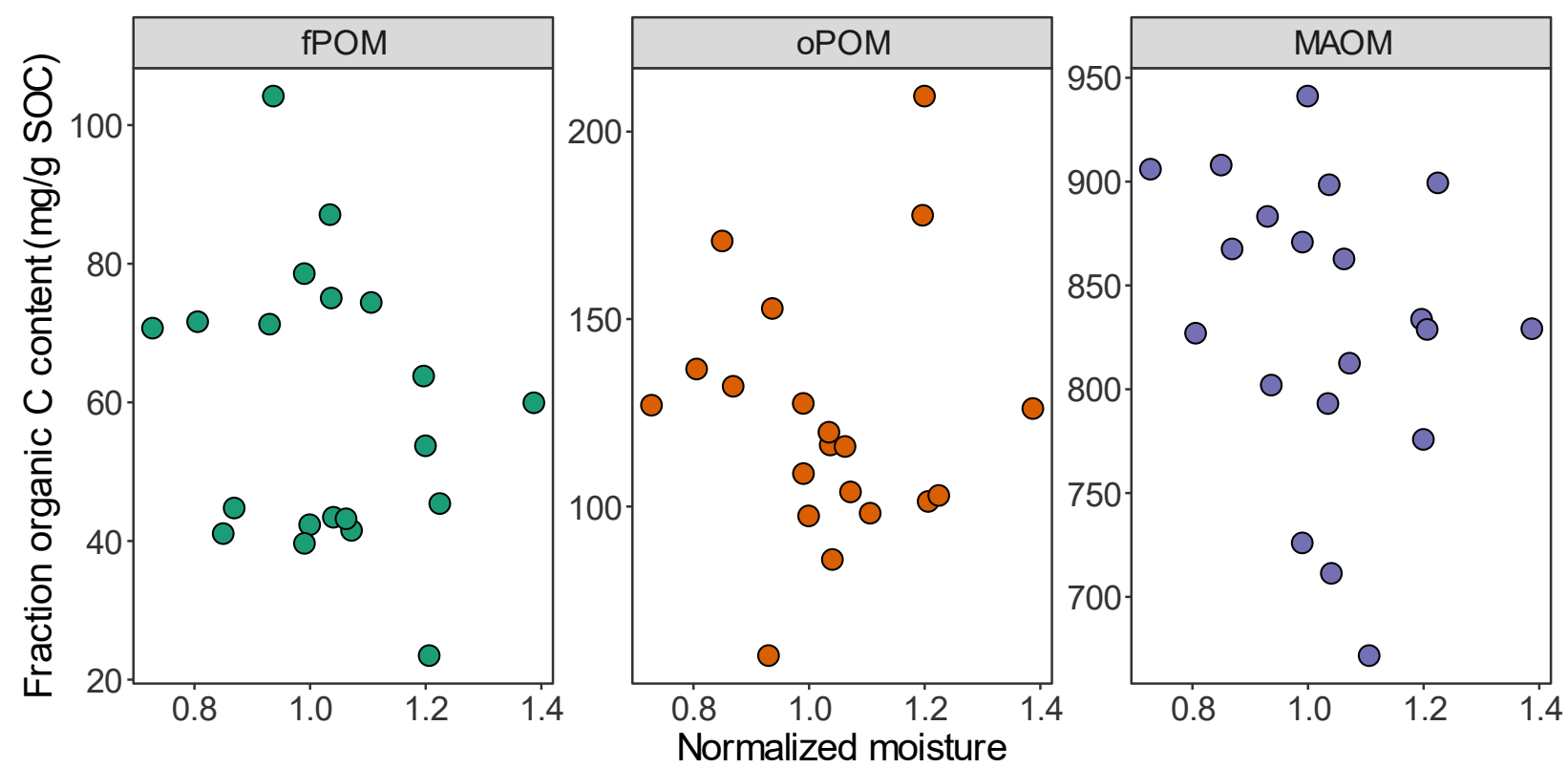

Figure S2. Organic carbon content in free particulate, occluded particulate, and mineral associated organic matter fractions (( $P P O M$, oPOM, and MAOM, respectively), relative to total SOC, as a function of normalized soil moisture values. Regression models were non-significant. 
This is a preprint submitted to Earth ArXiv and has not been peer reviewed

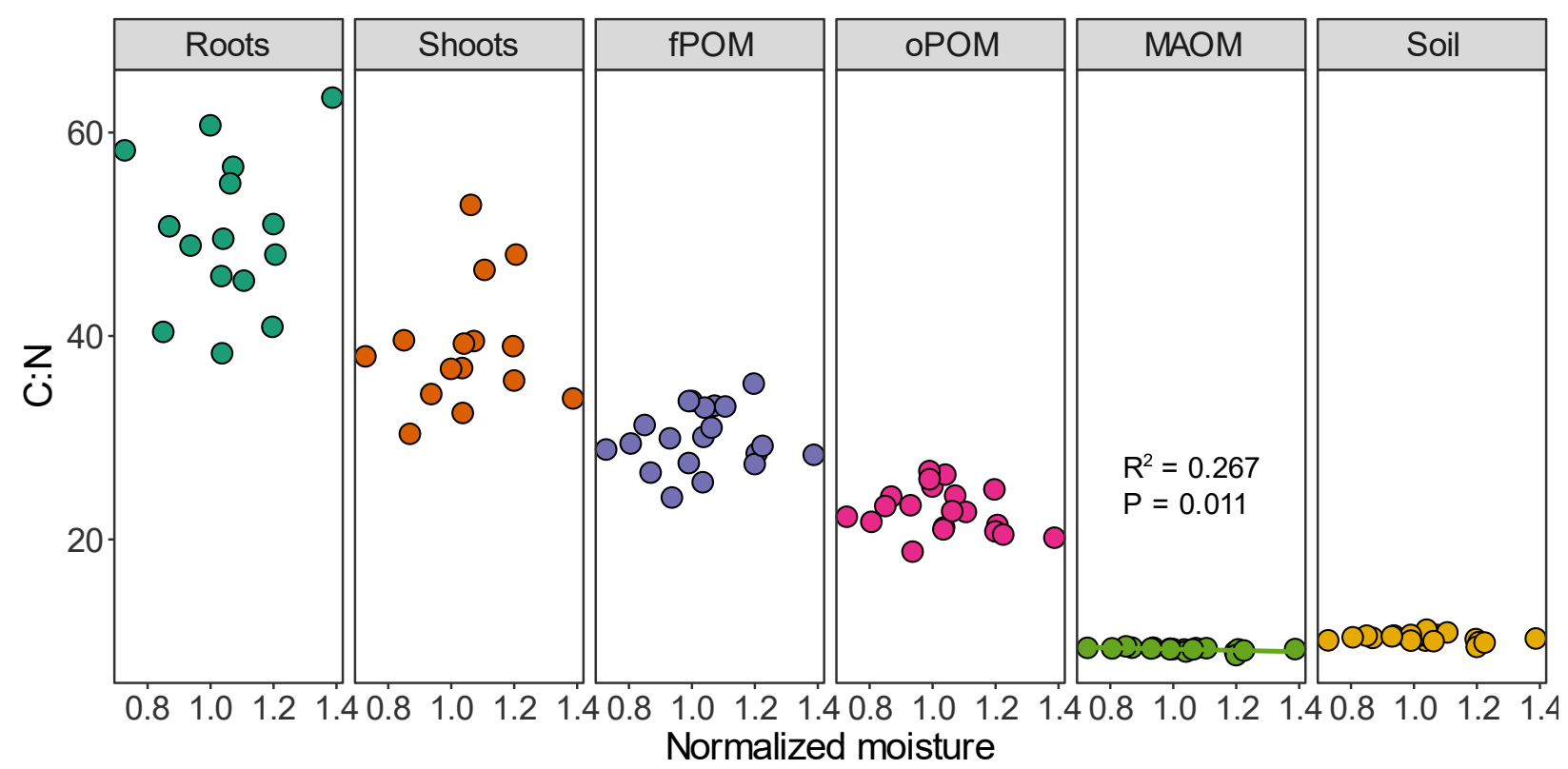

777 Figure S3. C:N ratio of plant biomass, and free particulate, occluded particulate, and mineral associated organic matter fractions (( $P$ POM, oPOM, and MAOM, respectively) as function of normalized soil moisture values. Significant regression models are shown with regression lines, regression coefficients, and $P$ 780 values. 


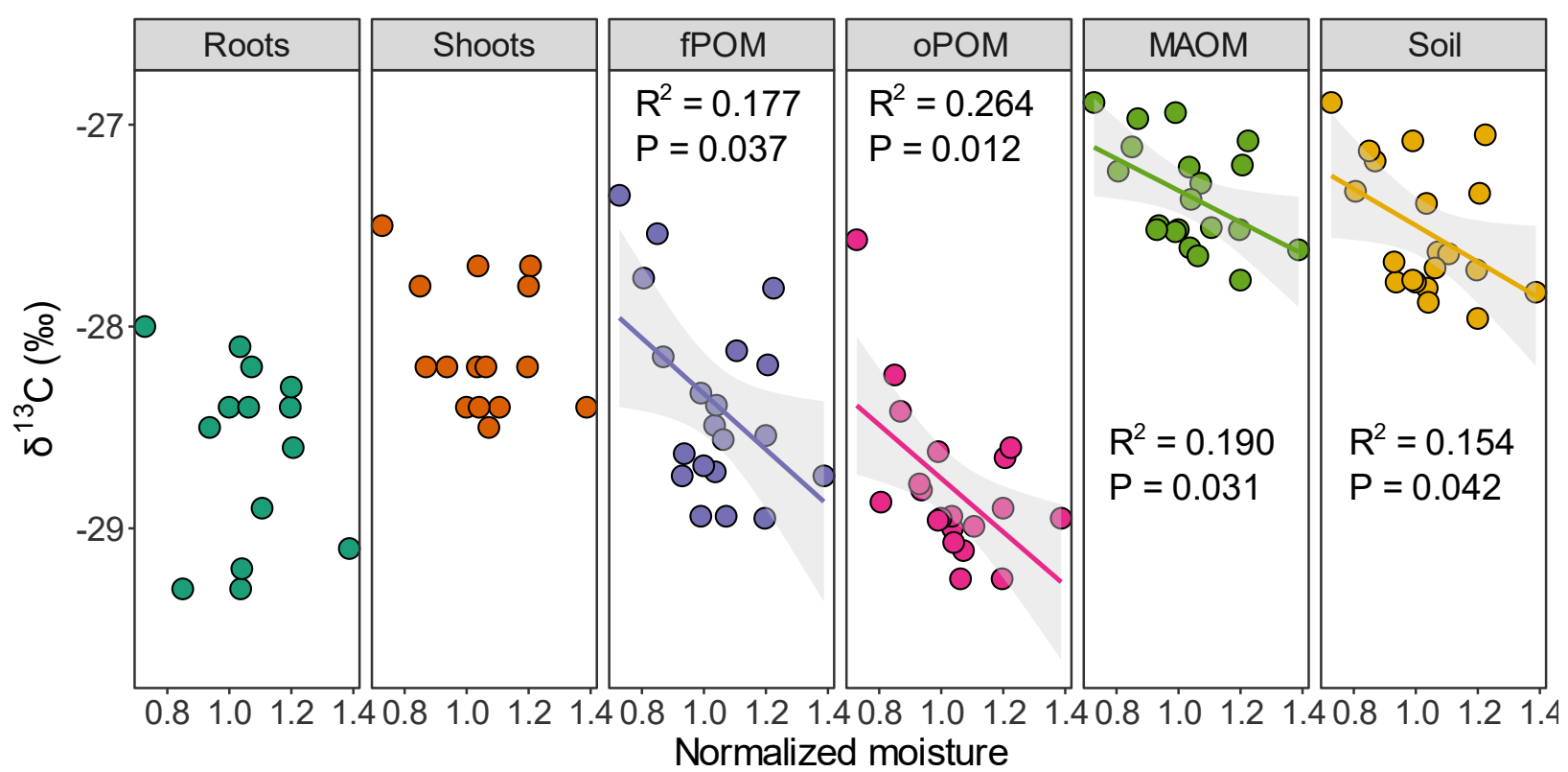

784 Figure S4. $\delta^{13} \mathrm{C}$ values of plant biomass, and free particulate, occluded particulate, and mineral associated organic matter fractions (( $P O M$, oPOM, and MAOM, respectively) as function of normalized soil moisture values. Significant regression models are shown with regression lines, regression coefficients, and $P$ values. 
This is a preprint submitted to Earth ArXiv and has not been peer reviewed

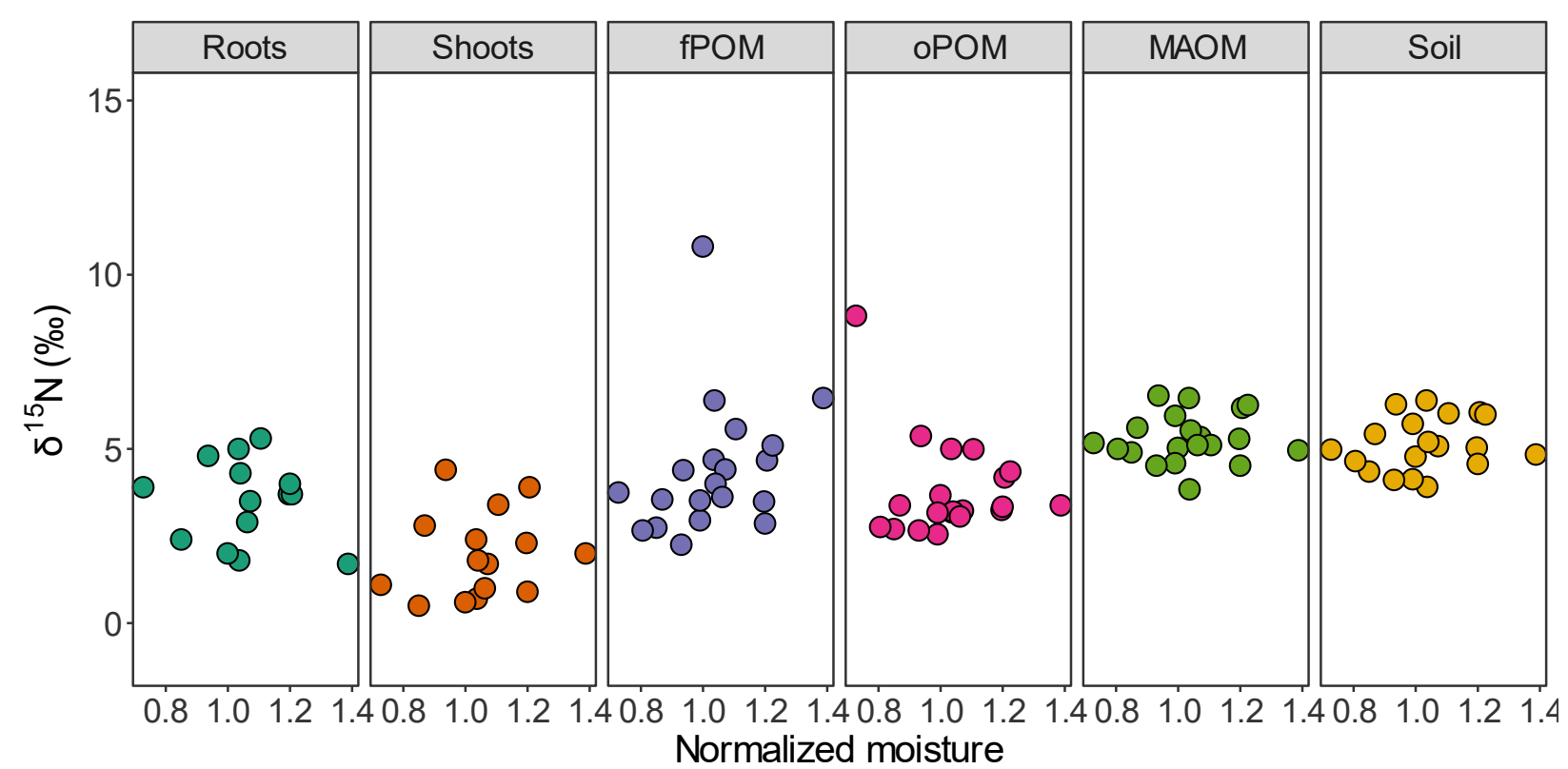

Figure S5. $\delta^{15} \mathrm{~N}$ values of plant biomass, and free particulate, occluded particulate, and mineral associated organic matter fractions (( $P P O M, o P O M$, and MAOM, respectively) as function of normalized soil moisture values. Significant regression models are shown with regression lines, regression coefficients, and P values. 


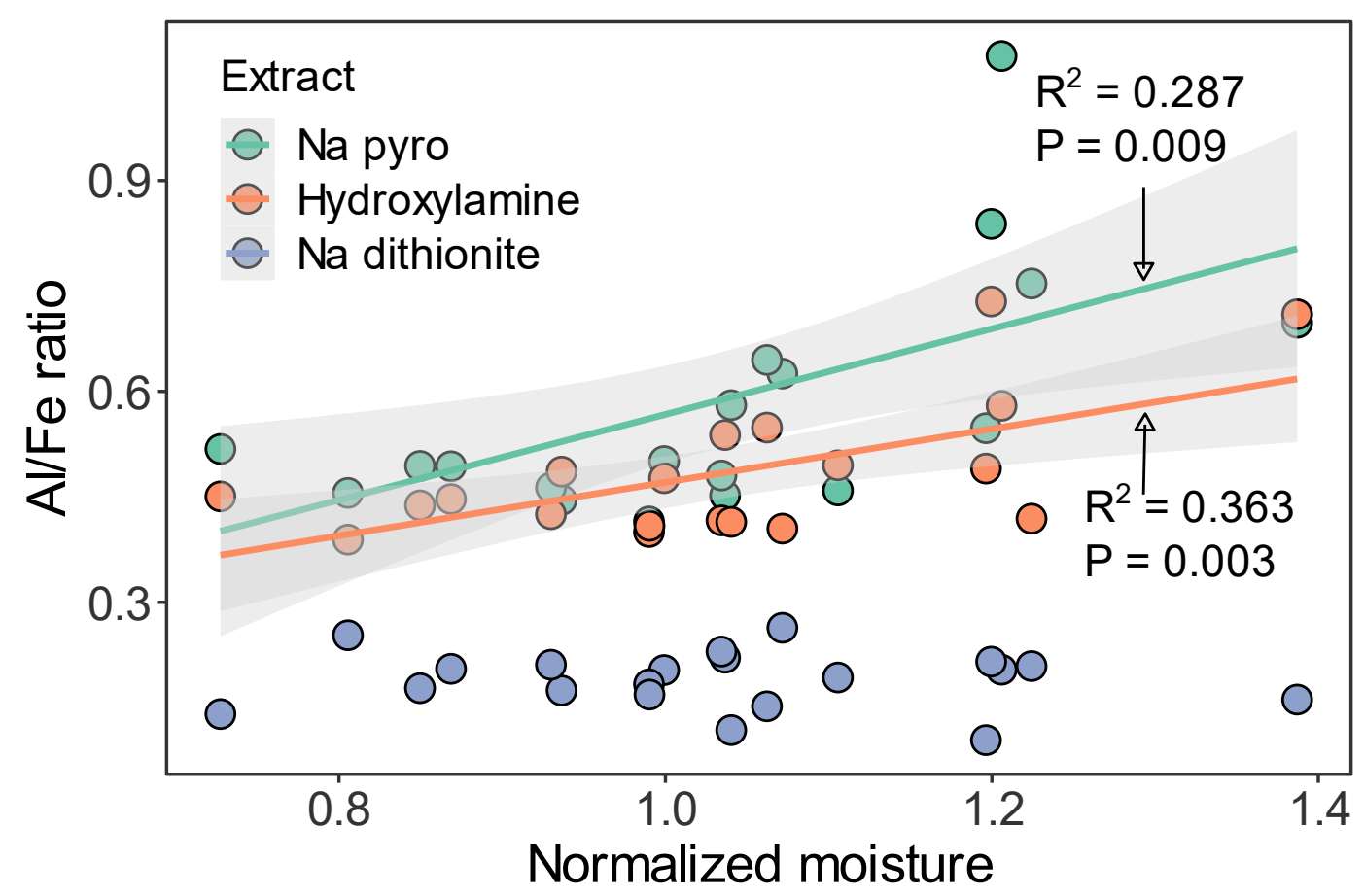

Figure S6. Al/Fe ratio in different oxide extractions as a function of normalized soil moisture values. 
This is a preprint submitted to Earth ArXiv and has not been peer reviewed

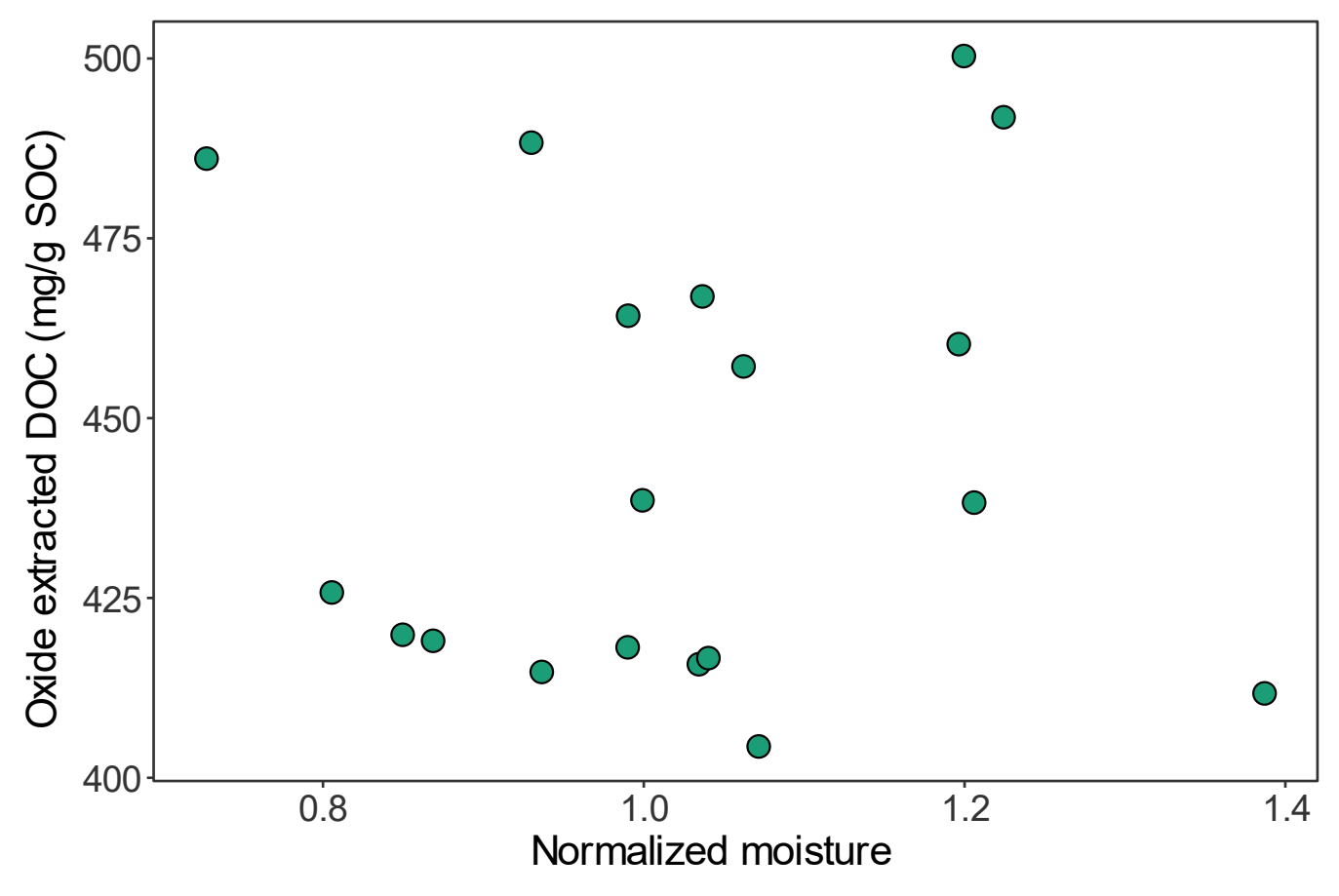

799 Figure S7. Total dissolved organic carbon (DOC) normalized to mass of soil organic carbon (SOC) as a 800 function of normalized soil moisture values. Regression model was non-significant. 
This is a preprint submitted to Earth ArXiv and has not been peer reviewed
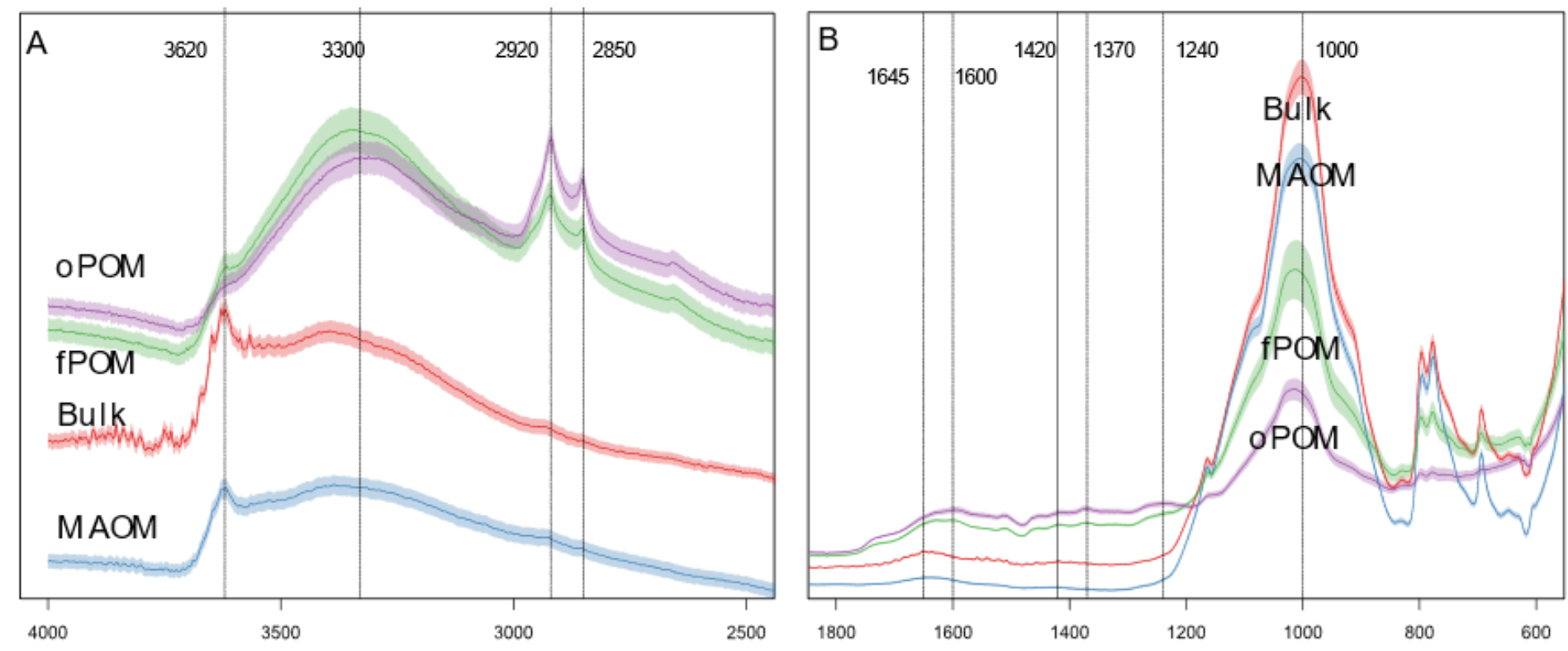

802

803 Figure S8. ATR-FTIR spectra in the range of $2500-40000 \mathrm{~cm}^{-1}$ (A) and in the range of $550-1840 \mathrm{~cm}^{-1}$ 804 (B) of bulk soils and MAOM fractions $(n=20)$ and fPOM and oPOM fractions $(n=3)$ averaged across all 805 long-term normalized moisture values.

806 
This is a preprint submitted to Earth ArXiv and has not been peer reviewed

Low moisture

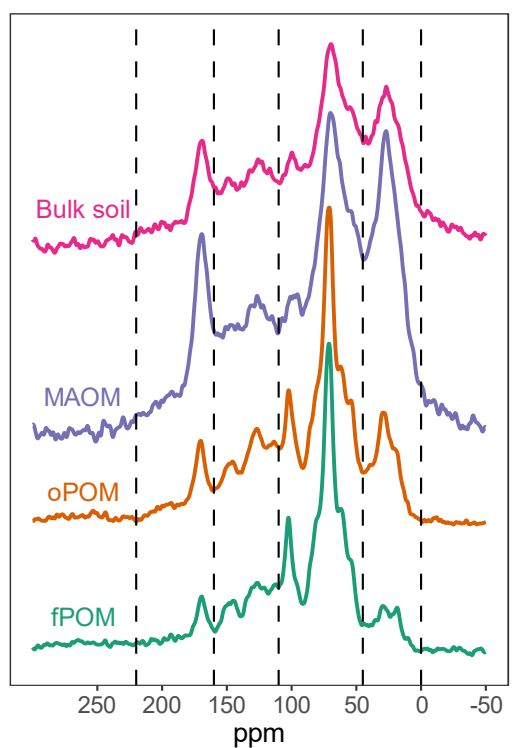

Medium moisture

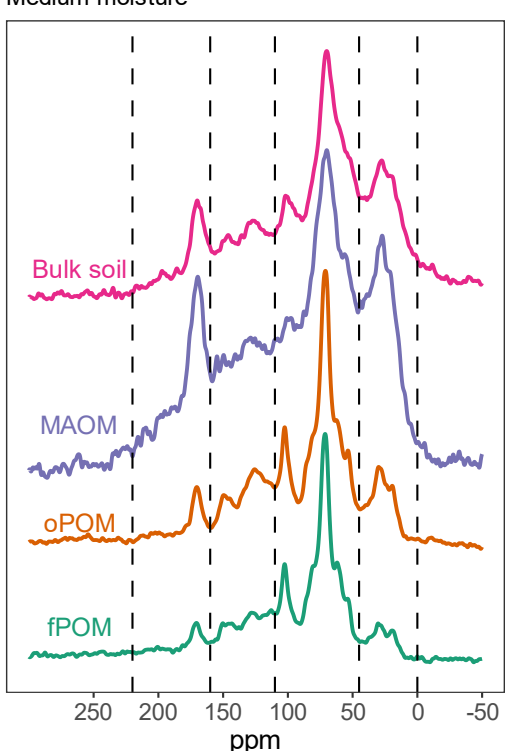

High moisture

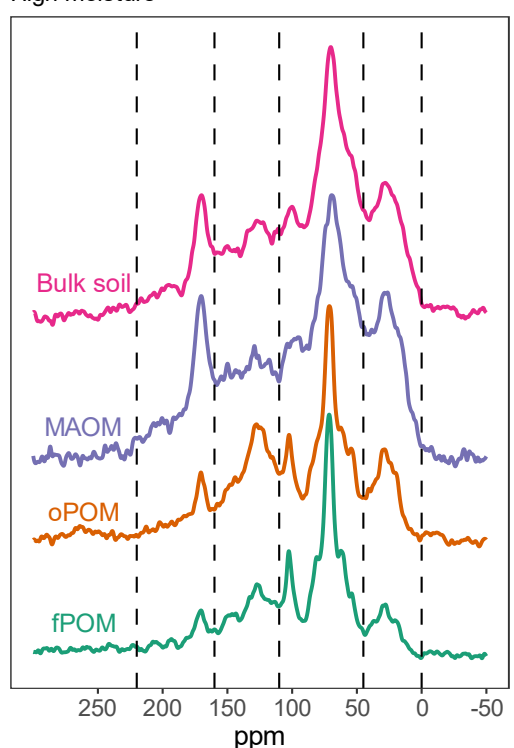

Figure S9. ${ }^{13}$ C NMR spectra of $P P O M$, oPOM, MAOM, and bulk soils from composited sampled from low, 809 mid, and high moisture levels. 
This is a preprint submitted to Earth ArXiv and has not been peer reviewed

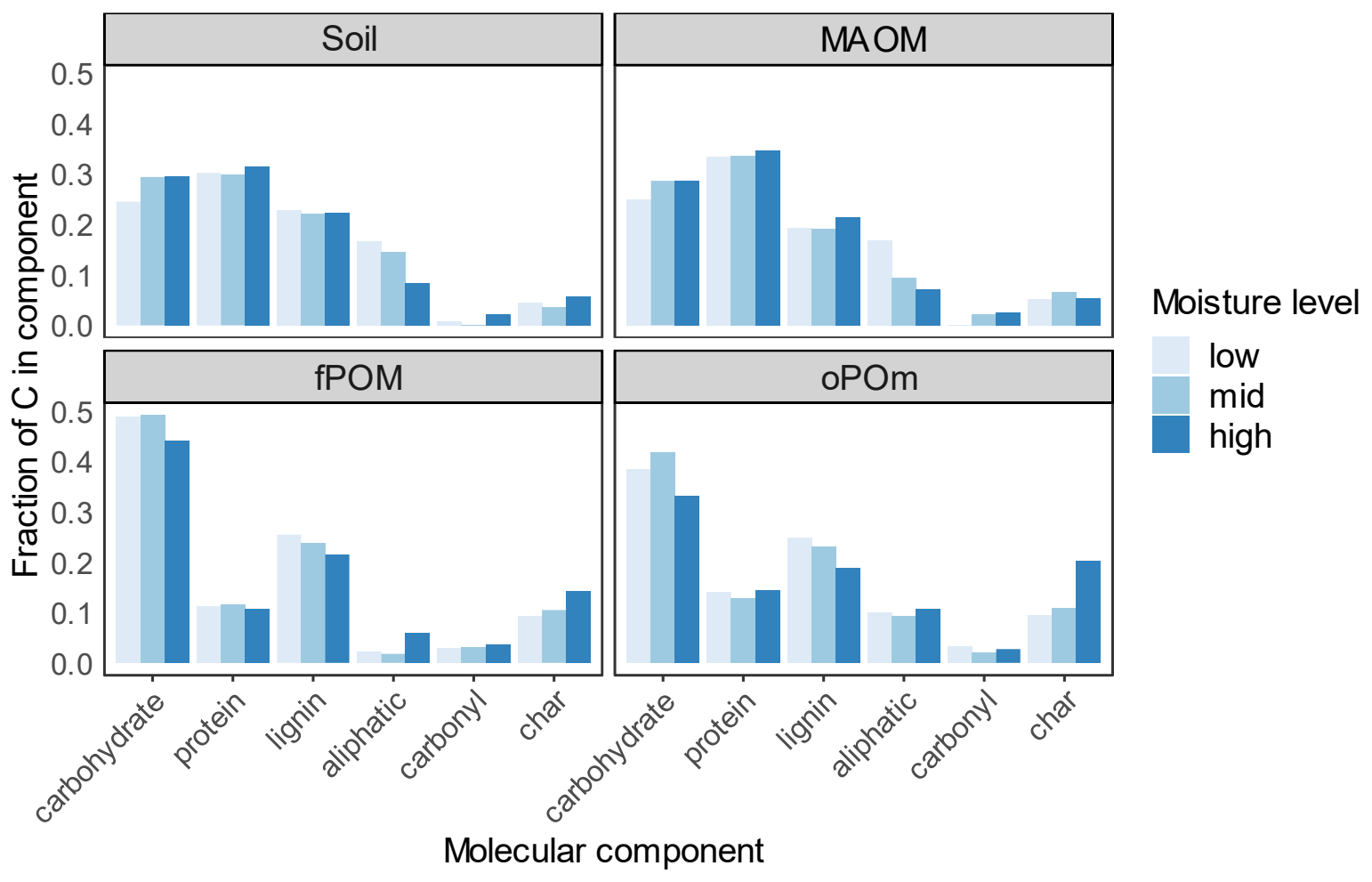

812 Figure S10. Molecular mixing model results for ${ }^{13} C$-NMR analysis. Relative amount of $C$ in different 813 molecular components for each soil fraction and normalized moisture level. 


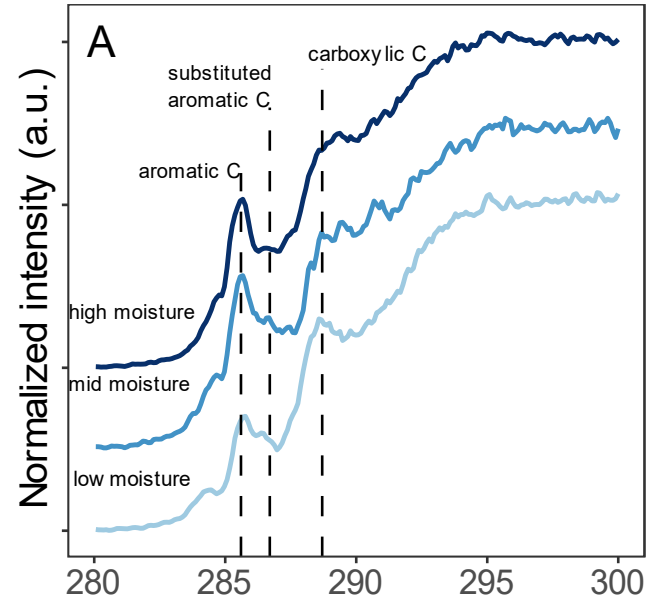

816
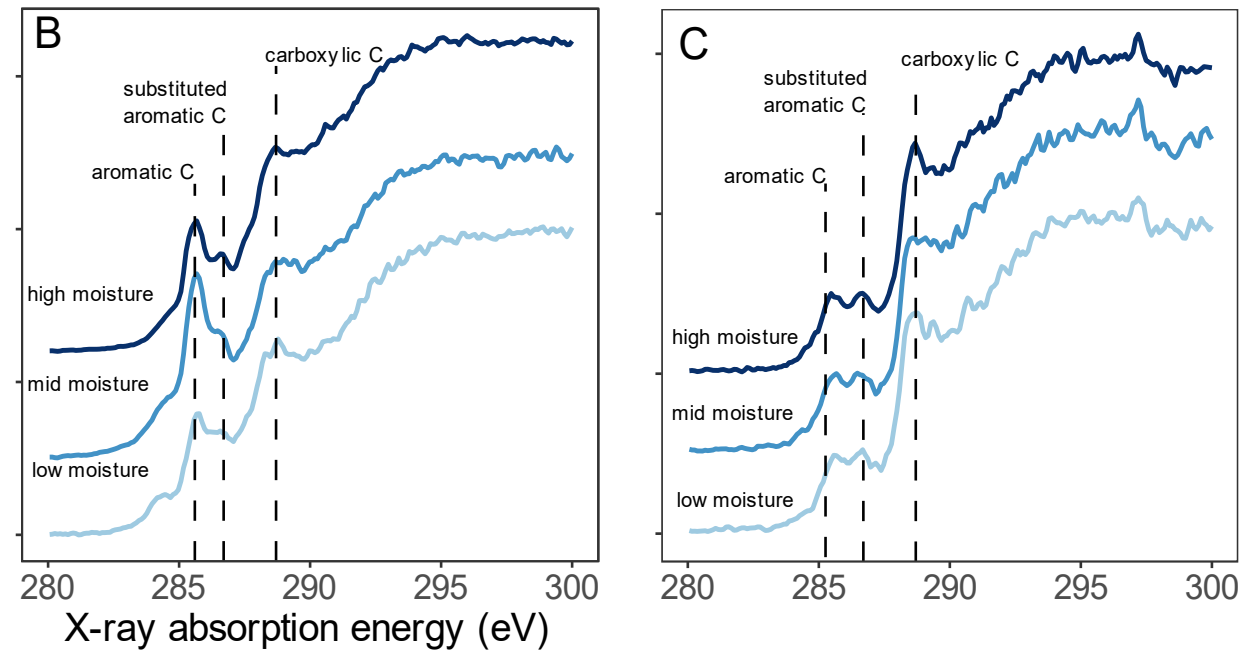

817 Figure S11. C K-edge NEXAFS spectra of fPOM, oPOM, and MAOM fractions from low, mid, and high 818 moisture levels. 
This is a preprint submitted to Earth ArXiv and has not been peer reviewed

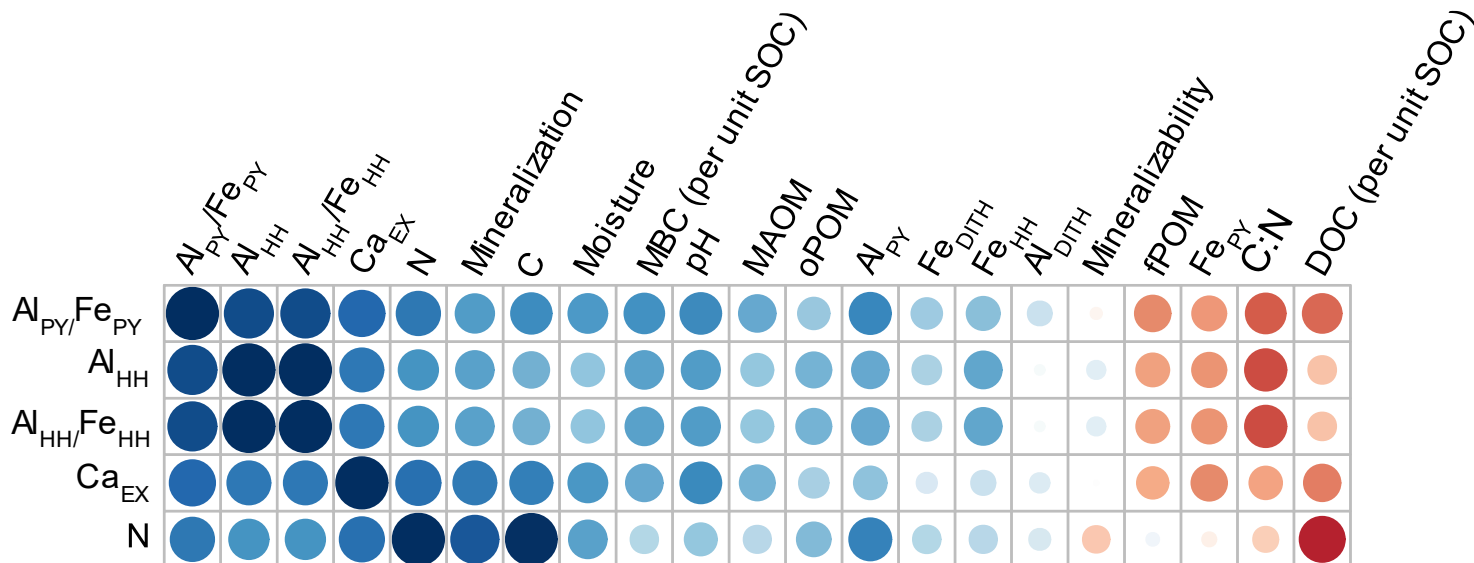

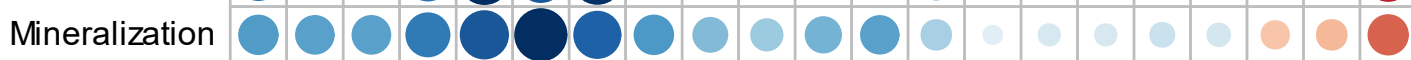

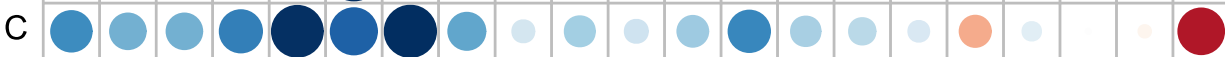

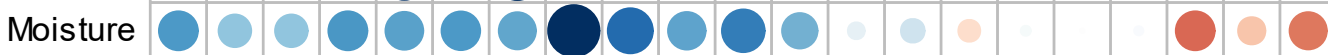

\begin{tabular}{|l|l|l|l|l|l|l|l|l|} 
MBC (per unit SOC) & 00000000
\end{tabular}

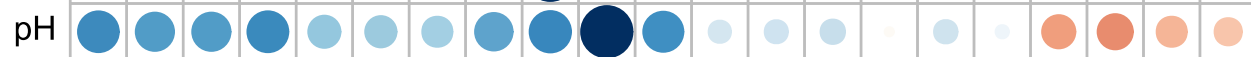

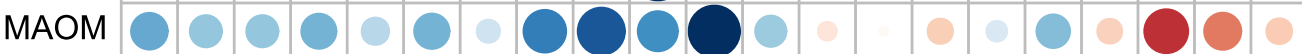

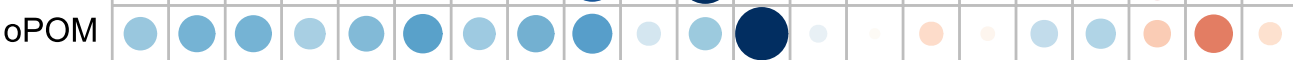

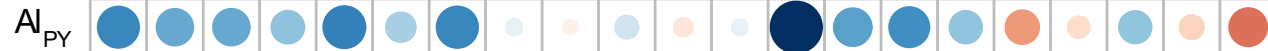

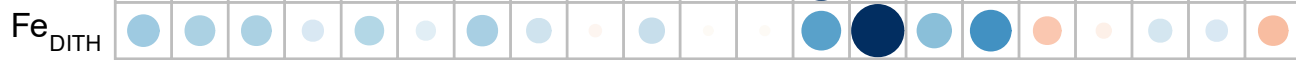

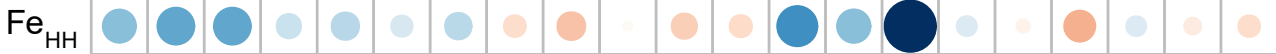

$\mathrm{Al}_{\mathrm{DITH}}$

Mineralizability

fPOM

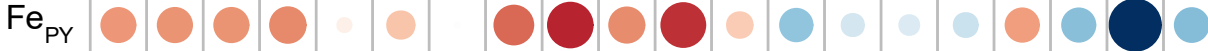

$\mathrm{C:N}$

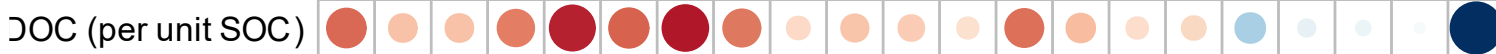

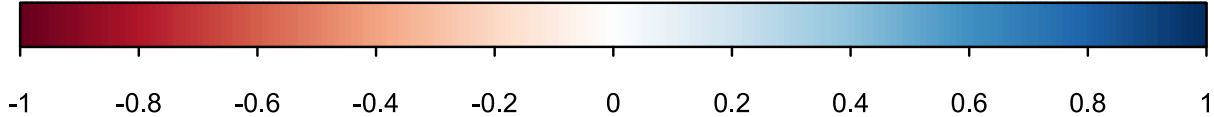

Figure S12 Heatmap of Pearson correlations (r). 